NBER WORKING PAPER SERIES

\title{
ADVERSE SELECTION AND AN INDIVIDUAL MANDATE: WHEN THEORY MEETS PRACTICE
}

\author{
Martin B. Hackmann \\ Jonathan T. Kolstad \\ Amanda E. Kowalski \\ Working Paper 19149 \\ http://www.nber.org/papers/w19149 \\ NATIONAL BUREAU OF ECONOMIC RESEARCH \\ 1050 Massachusetts Avenue \\ Cambridge, MA 02138 \\ June 2013
}

We thank Kate Archibald and Xu "Sophie" He for excellent research assistance. This project has benefited greatly from comments from Marika Cabral, Keith Ericson, Mathis Wagner, Ebonya Washington, and Heidi Williams. We are also grateful for comments by seminar participants at Yale and the University of Pennsylvania and participants at the health care markets conference at the Kellogg School of Management. Funding from the Robert Wood Johnson Foundation and the National Institute on Aging grant \#P30 AG012810 is gratefully acknowledged. The views expressed herein are those of the authors and do not necessarily reflect the views of the National Bureau of Economic Research.

NBER working papers are circulated for discussion and comment purposes. They have not been peerreviewed or been subject to the review by the NBER Board of Directors that accompanies official NBER publications.

(C) 2013 by Martin B. Hackmann, Jonathan T. Kolstad, and Amanda E. Kowalski. All rights reserved. Short sections of text, not to exceed two paragraphs, may be quoted without explicit permission provided that full credit, including $\odot$ notice, is given to the source. 
Adverse Selection and an Individual Mandate: When Theory Meets Practice

Martin B. Hackmann, Jonathan T. Kolstad, and Amanda E. Kowalski

NBER Working Paper No. 19149

June 2013

JEL No. I11,I13,I18

\begin{abstract}
We develop a model of selection that incorporates a key element of recent health reforms: an individual mandate. We identify a set of key parameters for welfare analysis, allowing us to model the welfare impact of the actual policy as well as to estimate the socially optimal penalty level. Using data from Massachusetts, we estimate the key parameters of the model. We compare health insurance coverage, premiums, and insurer average health claim expenditures between Massachusetts and other states in the periods before and after the passage of Massachusetts health reform. In the individual market for health insurance, we find that premiums and average costs decreased significantly in response to the individual mandate; consistent with an initially adversely selected insurance market. We are also able to recover an estimated willingness-to-pay for health insurance. Combining demand and cost estimates as sufficient statistics for welfare analysis, we find an annual welfare gain of \$335 dollars per person or $\$ 71$ million annually in Massachusetts as a result of the reduction in adverse selection. We also find evidence for smaller post-reform markups in the individual market, which increased welfare by another \$107 dollars per person per year and about \$23 million per year overall. To put this in perspective, the total welfare gains were $8.4 \%$ of medical expenditures paid by insurers. Our model and empirical estimates suggest an optimal mandate penalty of $\$ 2,190$. A penalty of this magnitude would increase health insurance to near universal levels. Our estimated optimal penalty is higher than the individual mandate penalty adopted in Massachusetts but close to the penalty implemented under the ACA.
\end{abstract}

Martin B. Hackmann

Department of Economics

Yale University

37 Hillhouse Avenue

Box 208264

New Haven, CT 06520

martin.hackmann@yale.edu

Jonathan T. Kolstad

The Wharton School

University of Pennsylvania

306 Colonial Penn Center

3641 Locust Walk

Philadelphia, PA 19104

and NBER

jkolstad@wharton.upenn.edu
Amanda E. Kowalski

Department of Economics

Yale University

37 Hillhouse Avenue

Box 208264

New Haven, CT 06520

and NBER

amanda.kowalski@yale.edu 


\section{Introduction}

An individual mandate that requires individuals to purchase health insurance or pay a penalty is a centerpiece of both the Affordable Care Act (ACA) of 2010 and the Massachusetts health reform of 2006. The individual mandate was also at the heart of the legal challenges to the ACA, and the mandate was upheld as constitutional by the Supreme Court in June 2012. Economic theory has long held that mandates can reduce the welfare loss from adverse (or advantageous) selection in insurance markets (see e.g. Akerlof (1970) and Rothschild and Stiglitz (1976)). On the other hand, recent empirical work on adverse selection finds relatively little welfare loss, suggesting otherwise. Reconciling these two views is both of interest to economists and highly relevant in light of the reliance on an individual mandate in both reforms.

The Massachusetts experience gives us a novel opportunity to examine how the mandate affected selection and welfare. We develop a simple model that allows us to not only test for the existence and sign (adverse or advantageous) of selection but also to recover the welfare impact of a mandate in the presence of selection. We extend the "downward sloping average cost curve test" proposed by Einav et al. (2010a), henceforth "EFC". EFC stipulates that if the average cost of the insured decreases as coverage increases - in our case, from before reform to after reform - then we know that healthier people entered the insurance pool, and the initial market was adversely selected. Conversely, an increase in average cost would indicate that the market was advantageously selected. We extend the EFC model to incorporate key features of health reform in practice: the individual mandate and insurer markups. Adding theoretical and empirical content to the model allows us to examine the impact of the mandate on social welfare in Massachusetts and to compute the socially optimal penalty; that is, the penalty that induces the efficient market equilibrium level of coverage. Our approach allows us to recover a small set of sufficient statistics to analyze the welfare impact in Massachusetts: the slopes of the insurance demand curve, average cost curve, and marginal cost curve, as well as the magnitude of the individual mandate penalty.

We contribute to the small but growing literature on the welfare cost of adverse selection in insurance markets (see Einav et al. (2010b) for a review and Bundorf et al. (2012), Einav et al. (2010c), and Beauchamp and Wagner (2012) for recent additions). Most papers in the literature examine selection within a set of plans offered by employers and generally find that the 
welfare cost of adverse selection is small in that context (e.g. EFC and Bundorf et al. (2012)). However, the distinction between different employer-sponsored health insurance plans is less stark than the distinction between having health insurance and not having it at all. The welfare cost of adverse selection on the intensive margin between plans may differ, potentially substantially, from the welfare impact on the extensive margin. Moving beyond plan choices within employers is also important as the welfare cost of adverse selection could be much higher in the individual health insurance market than it is in the employer-sponsored market, at least to the extent that employers are natural pooling mechanisms. A primary contribution of our paper is our use of the Massachusetts health reform to examine adverse selection on the extensive margin in the individual health insurance market, where the welfare cost of adverse selection is thought to be the greatest.

Applying the theory to the data, we estimate the slopes of the average cost and demand curves using insurer enrollment, premium, and health expenditure information using data from regulatory filings of insurance companies, compiled by SNL Financial. We combine the enrollment information from the SNL data with coverage information from the National Health Interview Survey (NHIS). Both data sets distinguish between the individual and group (employer) insurance markets, allowing us to model the impact of reform on the individual market separately.

To model demand, we treat the individual penalty as an effective change in price in Massachusetts. Since the Massachusetts reform was implemented at the state level, we can control for other trends in the market for health insurance affecting the U.S. as a whole using data from other states. Using a similar strategy, we also recover the change in the average and marginal per capita cost of the insured population from before to after reform. Combined with the change in coverage, we can estimate the slope of the insurance demand and the cost curves; the key sufficient statistics to evaluate the welfare impact of Massachusetts reform.

Our empirical estimates suggest that Massachusetts individual market was adversely selected prior to health reform. ${ }^{1}$ We find that the individual mandate reduced adverse selection and increased annual welfare by $\$ 335$ per person in the individual market, which translates into an overall annual welfare gain of $\$ 71$ million. We also find evidence for smaller post-reform markups in the individual market, which increased welfare by another $\$ 107$ dollars per person per year and about

\footnotetext{
${ }^{1}$ This is consistent with previous work where we found evidence for adverse selection in Massachusetts pre-reform insurance market (Hackmann et al. (2012)). However, that paper focused solely on hospital cost and did not address the welfare impact of the change in selection; the key goal of this work.
} 
$\$ 23$ million per year overall. To put this in perspective, the total welfare gains were $8.4 \%$ of medical expenditures paid by insurers, and the welfare gains from reductions in adverse selection alone were $6.4 \%$ of medical expenditures paid by insurers. Finally, our model and empirical estimates suggest an optimal mandate of $\$ 2,190$ per year, which increases health insurance coverage levels in the individual market to universal levels. This is higher than the individual mandate penalty adopted in Massachusetts but very close to the penalty implemented under the ACA.

The remainder of this paper is organized as follows. Section 2 describes the institutional background of the individual mandate. In Section 3 we develop a simple model of adverse selection with an individual mandate, and in Section 4 we describe the estimation of the model. Section 5 describes the data, and Section 6 presents the results. Finally, we conduct a series of robustness checks in Section 7, and Section 8 concludes.

\section{Institutional Background on the Massachusetts Health Reform}

The Massachusetts health reform, which was signed into law in April 2006, became a model for the national reform (the ACA), which was enacted four years later in March 2010. Kolstad and Kowalski (2012a,b) discuss these reforms in depth. Here, we focus on the features of the Massachusetts reform and health insurance environment that are relevant to adverse selection in the individual health insurance market.

An individual mandate was the key feature of both reforms. In Massachusetts, the individual mandate requires that almost all non-poor residents either purchase a health insurance plan that meets minimum coverage criteria defined in the "Minimum Creditable Coverage" (MCC) plan or pay a penalty. Specifically, non-exempt individuals that do not have proof of sufficient health insurance coverage when they file their income taxes are charged an income- and age-dependent penalty of up to $50 \%$ of the lowest-priced plan available in the Massachusetts health insurance exchange market. Table 1 summarizes the respective penalties for the year $2012 .^{2}$ Individuals that earn less than $150 \%$ of the federal poverty line (FPL) are exempt from the penalty. The reform makes this population eligible for Medicaid or full premium discounts. ${ }^{3}$

\footnotetext{
${ }^{2}$ See http://www .massresources.org/health-reform.html.

${ }^{3}$ Individuals that earn less than $100 \%$ of the FPL became eligible for Medicaid, and individuals that earn between $100 \%$ and $150 \%$ of the FPL became eligible for full premium discounts. Individuals can also claim exemption for religious reasons or because of different affordability criteria using the Certificate of Exemption Application, available
} 
Table 1: Tax Penalty

\begin{tabular}{|c|c|c|c|c|c|}
\hline \multirow{2}{*}{ Income and Age } & $\mathbf{1 5 0 . 1 - 2 0 0 \% ~ F P L ~}$ & \multirow{2}{*}{$\mathbf{2 0 0 . 1 - 2 5 0 \%}$ FPL } & \multirow{2}{*}{$\mathbf{2 5 0 . 1 - 3 0 0 \% ~ F P L ~}$} & \multicolumn{2}{|c|}{ Above 300\% FPL } \\
\cline { 4 - 5 } & & & Age 18-26 & Age 27+ \\
\hline \multirow{2}{*}{ Tax penalty } & $\$ 19$ per month & $\$ 38$ per month & $\$ 58$ per month & $\$ 83$ per month & \$105 per month \\
\cline { 2 - 5 } & $\$ 228$ per year & $\$ 456$ per year & $\$ 696$ per year & $\$ 996$ per year & \$1260 per year \\
\hline
\end{tabular}

The mandate is particularly important for individuals and families who do not have access to employer-sponsored health insurance and must purchase health insurance through the individual market instead. These people face higher annual premiums than those with employer-sponsored health insurance. Moreover, they are exposed to the full cost of health insurance, unlike employees, who have access to the tax advantage for employer sponsored health insurance. Figure 1 lends empirical support to this appraisal using data from the National Health Interview Survey (NHIS) for individuals whose family income exceeds $300 \%$ of the federal poverty line. We compare insurance coverage trends for consumers who are offered health insurance through their employer (group market) with trends for consumers who must purchase their health insurance individually (individual market). The vertical lines separate the pre-reform and the post-reform years. Consequently, the years 2006 and 2007 represent the reform implementation years. Comparing coverage trends in the individual market with coverage trends in the group market allows us to document two important stylized facts. First, health insurance coverage is substantially higher in the group market both in Massachusetts and nationally. Second, the impact of Massachusetts health reform on health insurance coverage for the non-poor population is much larger in the individual market than the group market. We see a large coverage increase in the Massachusetts individual market relative to the national individual market following health reform, whereas the coverage increase in the group market is much smaller. This is not particularly surprising given that insurance coverage in Massachusetts group market was already close to universal levels prior to health reform. Therefore, we expect that the effects of selection, and consequently the welfare effects from the individual mandate, are small in the group market and focus our empirical analysis on the individual market. We provide our methodology for classifying individuals as members of the individual or group pools in Section 5.

at http://tinyurl.com/awmjfyo (Accessed September 17th, 2012.) 

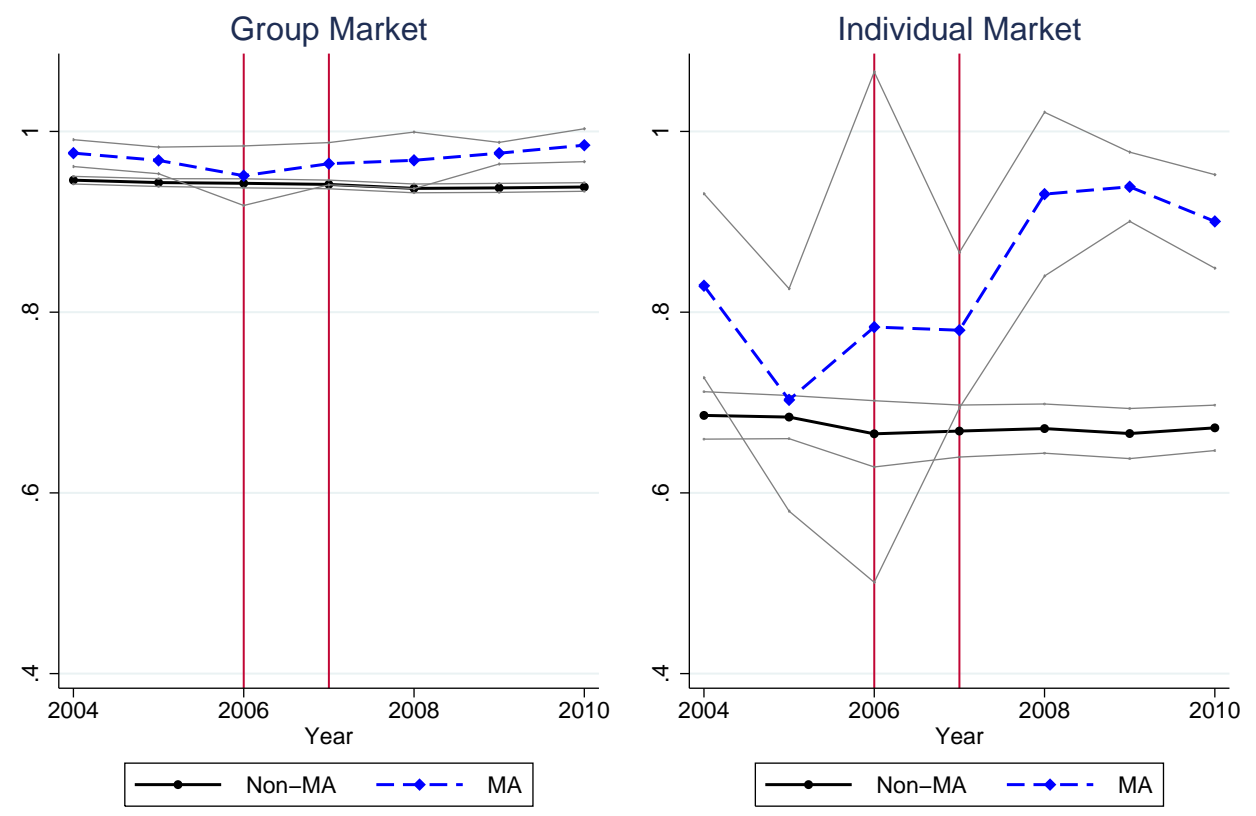

Another element of the Massachusetts health reform is the introduction of a health insurance exchange market: the Commonwealth Choice program. This exchange market aims to facilitate access to health insurance for consumers in the individual market as well as small employers (up to 50 employees). For more details see Ericson and Starc (2012) who study consumer response to the specific pricing rules employed by the Massachusetts Connector. ${ }^{4}$ The platform simplifies the comparison of insurance plans across and within carriers which may encourage competition and lead to smaller differences between premiums and average costs in the post-reform years. Smaller differences between premiums and average costs in the individual market are also consistent with newly imposed restrictions in the premium rating methodology. The health reform requires insurance carriers to use the same premium rating methodologies for small employers and individuals that purchase health insurance directly, see Gorman Actuarial et al. (2006) for details. This regulation may lower premiums in the individual market because insured employees in small businesses

\footnotetext{
${ }^{4}$ Discontinuities in pricing related to age allow them to estimate demand elasticity between plans. As with the literature discussed above, this demand elasticity is based on intensive margin choices between plan tiers and plan options.
} 
are younger and healthier on average. One advantage of our theory is that it allows us to capture the welfare gains from reduced adverse selection separately from the welfare gains from smaller differences between premiums and average costs.

Finally we emphasize two important regulations that may have exacerbated adverse selection in the pre-reform years: community rating and guaranteed issue.

Since 1996, Massachusetts has had community rating regulations in place, which restrict price differentiation across consumers within the same plan. Specifically, these regulations require health insurers in the individual market, which comprises consumers that are not offered health insurance through their employers, to charge the same price to individuals of the same age, see Wachenheim and Leida (2012). Across ages, premiums could only vary by up to a factor of two. This legislation benefits consumers with relatively high expected claim expenditures, who might face higher premiums than their less expensive peers otherwise.

Massachusetts has also had guaranteed issue regulations since 1996, which require insurers with at least 5,000 members to guarantee that any interested beneficiary could join the insurance pool. Combining these two regulations, we expect a disproportionately high share of consumers with high claim expenditures amongst the enrolled consumers in the pre-reform years. The Massachusetts reform retained these regulations. The ACA also established community rating and guaranteed issue regulations nationally, in addition to the individual mandate.

\section{Adverse Selection and an Individual Mandate in Theory}

In this section, we develop a simple model that incorporates both an individual mandate and insurer markups into the general model of adverse selection developed by EFC. This model addresses selection at the extensive margin but abstracts from selection amongst differentiated plans: the intensive margin. This modeling decision follows naturally from the policy intervention of interest, the individual mandate, which affects the demand for health insurance on the extensive margin. ${ }^{5}$

Using simple consumer and producer theory, we first derive the demand curve and then the average cost curve. We derive the welfare implications of an individual mandate using this framework. Next, we extend the framework to allow for insurer markups. Finally, we express the change

\footnotetext{
${ }^{5}$ We discuss these modeling decisions in further detail in the online appendix section A.1.
} 
in welfare and the optimal tax penalty in terms of sufficient statistics that can be estimated using a small number of moments in commonly available data.

\subsection{The Demand Curve}

In each period $t$, each consumer $i$ decides either to purchase a representative health insurance plan, $H_{i}=1$, or not to purchase the plan, $H_{i}=0$. We take the characteristics of the health insurance plan as given, and we assume for now that they do not change over time. We relax this assumption in our robustness checks, see Section 7.4. Consumers have an underlying type, $\theta_{i}$, which determines

their willingness to pay for insurance, $v\left(\theta_{i}\right)$, and the expected cost to health insurers on their behalf if they take up insurance, $c\left(\theta_{i}\right)$. The consumer type is potentially multi-dimensional and describes the individual's health profile and risk preferences, as well as other characteristics. Consumer type is distributed according to $G_{\theta}$ in the population. Each consumer solves the following maximization problem:

$$
\max _{H_{i}}\left\{X_{i}+v\left(\theta_{i}\right) * H_{i}\right\} \text { s.t. } Y_{i}=X_{i}+P * H_{i},
$$

where $Y_{i}$ measures income, $X_{i}$ is a numeraire good, and $P$ denotes the insurance premium that does not vary across individuals. The share of insured consumers at the market level, $I$, is as follows:

$$
I:=\int_{v(\theta)>P} d G_{\theta}
$$

To incorporate the impact of the individual mandate on consumer demand, we introduce a financial penalty, $\Pi$, paid by consumers who do not purchase health insurance. The mandate, because it changes the cost of not having health insurance, changes the budget constraint for an individual to $Y_{i}=X_{i}+P * H_{i}+\Pi *\left(1-H_{i}\right)$. Because purchasing insurance not only provides utility directly but also relaxes the budget individual's budget constraint, the penalty effectively lowers the price of insurance. Thus, insurance coverage at the market level with a mandate is:

$$
I:=\int_{v(\theta)>P-\Pi} d G_{\theta}
$$

We express the market level demand curve $P=D(I, \Pi)$. It is a function of insurance coverage at the market level, $I$, and the penalty associated with the individual mandate, $\Pi$, which is equal 
to zero in the period before the individual mandate is introduced and equal to $\pi$ in the post-reform period.

As illustrated in Figure 2, the individual mandate simply shifts the demand curve upward by the penalty amount, $\pi \cdot{ }^{6}$ In the pre-reform period $(t=p r e)$ before the individual mandate is introduced, consumer demand is captured by the lower demand curve. After reform is implemented $(t=p o s t)$, the tax penalty increases the demand for insurance because the outside option of going without health insurance is less attractive. Therefore, consumers are willing to pay an extra amount, up to $\pi$, to avoid the tax penalty; the higher demand curve in Figure 2.

\subsection{The Average Cost Curve}

We assume that providers offer insurance plans that are homogeneous with respect to plan generosity. We also assume that insurers compete in prices and that they cannot condition their annual premium $P$ on an individual's expected insurable health care costs, $c\left(\theta_{i}\right)$, which is consistent with community rating regulation. ${ }^{7}$ In equilibrium, providers set the premium equal to average costs (average health care claim expenditures). We introduce additional markups that may cover fixed overhead and capital costs in the next section.

Following the outlined assumptions, we can express the market level average cost curve as a function of market level insurance coverage by

$$
A C(I)=\frac{1}{I} \int_{v(\theta)>D(I, 0)} c(\theta) d G_{\theta}
$$

In words, this equation expresses the average costs of consumers, who are purchasing health insurance at annual premiums $P=D(I, 0)$. By construction, these are the $I$ consumers with the highest willingness to pay. Here, we have used the fact that the mandate does not change the ordering of the consumers' willingness to pay for health insurance. This observation allows us to express the pool of insured consumers in terms of the pre-reform demand curve, $D(I, 0)$. That means that conditional upon the market level insurance coverage, $I$, the pool of consumers that purchase health insurance does not depend on the tax penalty, П. Therefore, the average costs of

\footnotetext{
${ }^{6}$ The depicted demand curves $D(I, 0)$ and $D(I, \pi)$ have the same linear functional form, which is an approximation to a more general nonlinear functional form.

${ }^{7}$ We discuss the role of age-specific price bands in the robustness check section.
} 
the insured consumers do not depend on the tax penalty either, which allows us to represent the average costs as a function of the market level insurance coverage only. Consequently, while the tax penalty induces a shift in the demand curve, it induces movement along the average cost curve.

Analogously, the marginal cost curve is given by

$$
M C(I)=E[c(\theta) \mid v(\theta)=D(I, 0)]
$$

Figure 2: Adverse Selection And The Mandate Without Markups

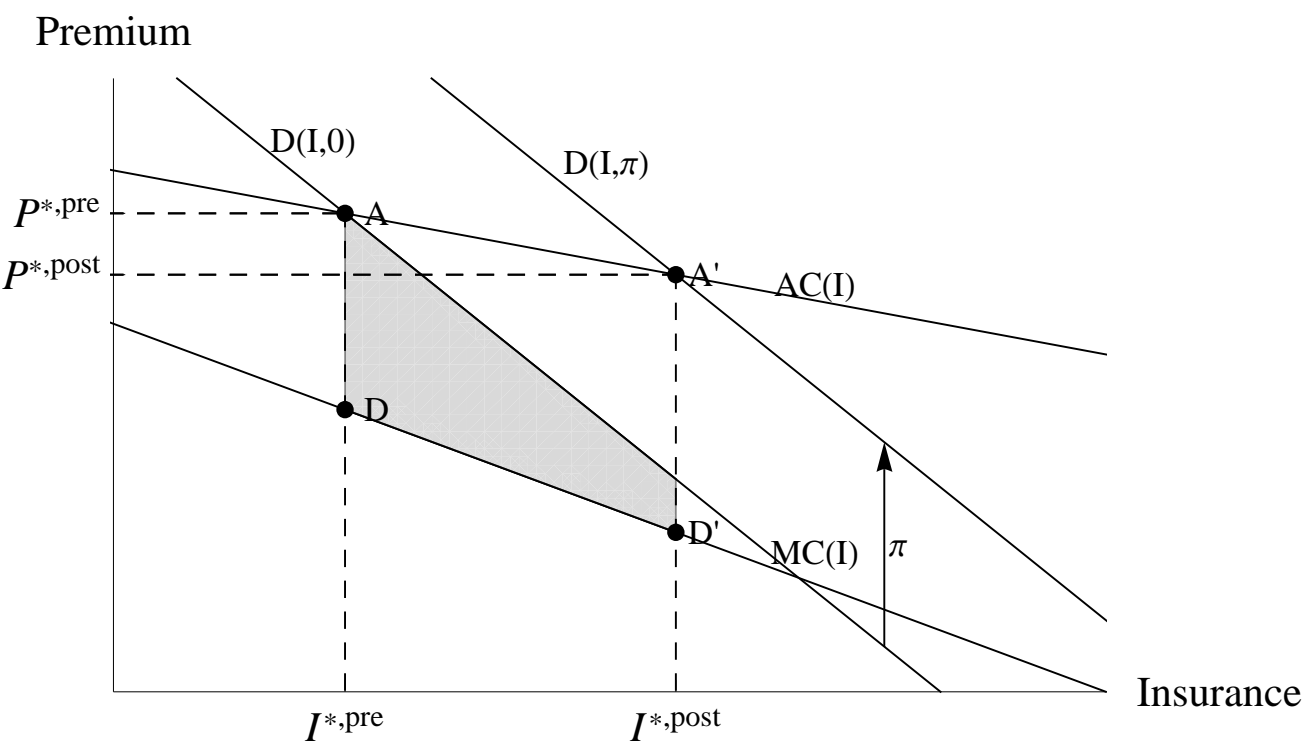

Consistent with our empirical evidence on adverse selection, discussed in Section 6, we display a downward sloping average cost curve in Figure 2. $I^{*}$ pre refers to the pre-reform equilibrium coverage; the point at which the pre-reform demand curve intersects with the average cost curve. $P^{*, p r e}$ is the premium in the pre-reform equilibrium where it is equal to average cost. The point on the $\mathrm{y}$-axis corresponding to point $\mathrm{D}$ is the marginal costs in the pre-reform equilibrium.

The tax penalty shifts out the market demand curve from $D(I, 0)$ to $D(I, \pi)$. In an adversely selected market as shown, equilibrium insurance coverage increases to $I^{*}$,post. The new equilibrium premium and the marginal cost are determined by the point at which the new demand curve intersects the old cost curves (shown by A' and D' respectively). 


\subsection{Welfare Implications of the Individual Mandate}

With the demand curve and the average cost curve, we can calculate the change in welfare introduced by the individual mandate. The change in welfare is given by the integral over the difference between the willingness to pay and the marginal costs for the newly insured consumers, as depicted by the gray area in Figure $2 .^{8}$ Intuitively, the welfare gains due to the individual mandate capture the extent to which the outward shift in demand induced by the penalty corrects existing adverse selection by moving individuals into coverage whose willingness-to-pay for insurance exceeds the marginal cost of insuring those individuals but for whom that average cost of insuring them is greater than their willingness-to-pay. We note also that an individual penalty can be large enough to induce additional consumers into the market for whom the marginal cost of insuring them is greater than their willingness-to-pay, inducing a welfare loss. We return to this issue in detail below when we derive the optimal penalty.

\subsection{Welfare Effects with Changes in Markups}

In this section, we extend our previous pricing model and allow insurers to charge a positive markup on top of average costs. Furthermore, we allow the markup to change in response to health reform. This extension is motivated by (i) the fact that markups are a well-documented feature of the insurance market (see e.g. Dafny (2010)) and (ii) the need to estimate the model in an empirical setting in which markups are a feature of the market.

Figure 3 captures these extensions and differs from Figure 2 in three important ways. First, in equilibrium, premiums may differ from average costs, which is why we introduce separate notation for average costs. While point A still refers to the premium in the pre-reform equilibrium, we introduce point $\mathrm{H}$ to refer to average costs in the pre-reform equilibrium. The vertical difference between point A and point H captures the markup. Similarly, points A' and H' refer to premiums and average costs in the post-reform equilibrium. Notice that we can construct a second point on the old demand curve, point $C$, if we subtract the observed tax penalty from the observed postreform premium. Therefore, the pre-reform and the post-reform equilibrium outcomes determine two points on the average cost curve and two points on the old demand curve, which allow us to estimate the slope and the intercept of these two structural equations.

\footnotetext{
${ }^{8} \mathrm{We}$ discuss this result in further detail in the online appendix section A.3.
} 
Second, we allow for different markups in the pre and the post-reform period. Specifically, the vertical difference between A' and H' may be smaller or larger than the vertical difference between A and $\mathrm{H}$. To the extent that the introduction of health exchanges decreased consumer search costs, increased competition, or otherwise altered market structure such that insurers cannot maintain pre-reform markups our model captures this effect. Third, the change in markups affects social welfare. A decrease in the markup, as shown in Figure 3, is not just a transfer from insurers to consumers. It increases social welfare in the presence of adverse selection because the size of the insured population expands.

To distinguish between the welfare effect from the removal of adverse selection and the welfare effect from an increase in competition, we add a pre-reform pricing curve in Figure 3. We simply add the pre-reform markup to the average cost curve to predict insurance coverage, premiums, and costs in the post-reform period under the pre-reform markup. Specifically, the intersection between the pre-reform pricing curve and the post-reform demand curve determines the insurance

coverage under the pre-reform markup, $I^{*}$ markup. Therefore, we attribute the welfare gain up to $I^{*, \text { markup }}$ to the removal of adverse selection and the additional increase up to $I^{*, \text { post }}$ to the smaller post-reform markup.

Graphically, we decompose the full welfare effect into two effects. The light gray area refers to the welfare gain from the removal of adverse selection, and the dark gray area measures the welfare gain from a decrease in the post-reform loading factor. We refer to the former effect as the net welfare effect.

\subsection{Sufficient Statistics for Welfare Analysis}

Having developed a model of adverse selection that captures the salient features of health reform (and, therefore, our empirical setting) we now turn to translating our model into a set of sufficient statistics. This approach allows us to estimate the welfare impact of reform using available data and a minimum of assumptions about the underlying structural preferences of consumers and competing insurers. We distinguish between the full welfare effect - capturing the total welfare impact of reform - and the net welfare effect — which is the welfare impact of reform solely due to changes in adverse selection. The latter welfare estimates nets out any welfare effects that result from changes in markups. Using the notation from Figure 3, we can express the full welfare effect as a 
Figure 3: Adverse Selection And The Mandate With Markups

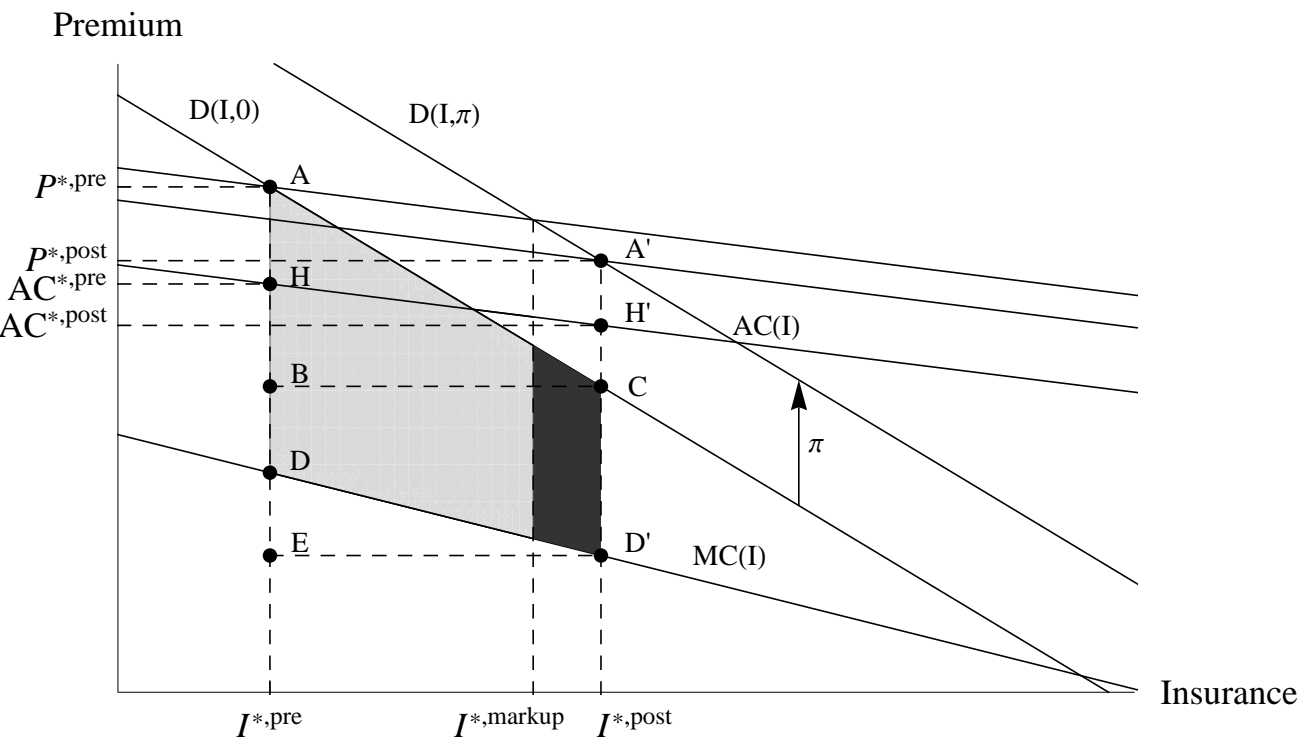

combination of two triangles and one rectangle:

$$
\Delta W_{\text {full }}=A B C+B E D^{\prime} C-D E D^{\prime}
$$

We are now able to express the full welfare change in terms of a small number of sufficient statistics: the change in coverage, premiums, and average costs between the pre-reform and the post-reform period, the pre-reform levels of coverage, premiums, and average costs, and the tax penalty. ${ }^{9}$

$$
\begin{aligned}
\Delta W_{\text {full }} & =\left(P^{*, \text { pre }}-A C^{*, \text { pre }}\right) *\left(I^{*, \text { post }}-I^{*, \text { pre }}\right) \\
& -\left(A C^{*, \text { post }}-A C^{*, \text { pre }}\right) *\left(I^{*, \text { pre }}+\left(I^{*, \text { post }}-I^{*, \text { pre }}\right)\right) \\
& +\frac{1}{2}\left(\left(P^{*, \text { post }}-\pi\right)-P^{*, \text { pre }}\right) *\left(I^{*, \text { post }}-I^{*, \text { pre }}\right) .
\end{aligned}
$$

Intuitively, this is because we can construct two points on the average cost and the old demand

\footnotetext{
${ }^{9}$ To see this, notice that the areas ABC and BED'C sum to the polygon AED'C. Subtracting the triangle DED' delivers the welfare-relevant area that combines the light gray and the dark gray area. As we demonstrate in Section A.4 of the online appendix, these welfare-relevant areas can be expressed in terms of small number of sufficient statistics.
} 
curve, which allow us to estimate these structural equations and to quantify the size of the welfare relevant polygons. Practically, we need information on 6 empirical moments to identify 2 intercept and slope parameters as well as the pre-reform and the post-reform markup.

Because the mechanisms for welfare improvements due to health reform differ substantially between reductions in adverse selection and changes in market competitiveness, we separate these two mechanisms in our model. Separating the two mechanisms theoretically also provides a basis for us to separate them empirically. We can express the net (of changes in competition) welfare effects as follows:

$$
\begin{aligned}
\Delta W_{\text {net }} & =\left(P^{*, \text { pre }}-A C^{*, \text { pre }}\right) *\left(I^{*, \text { markup }}-I^{*, \text { pre }}\right) \\
& -\frac{A C^{*, \text { post }}-A C^{*, \text { pre }}}{I^{*, \text { post }}-I^{*, \text { pre }}} *\left(I^{*, \text { pre }}+\left(I^{*, \text { markup }}-I^{*, \text { pre }}\right)\right) *\left(I^{*, \text { markup }}-I^{*, \text { pre }}\right) \\
& +\frac{1}{2} * \frac{\left(P^{*, \text { post }}-\pi\right)-P^{*, \text { pre }}}{I^{*, \text { post }}-I^{*, \text { pre }}} *\left(I^{*, \text { markup }}-I^{*, \text { pre }}\right)^{2} .
\end{aligned}
$$

Finally, we can express the post-reform coverage level under the pre-reform markup, $I^{*, \text { markup }}$, in terms of the same set of sufficient statistics:

$$
I^{*, \text { markup }}=I^{*, \text { pre }}+\pi \frac{\left(I^{*, \text { post }}-I^{*, \text { pre }}\right)}{\left(A C^{*, \text { post }}-A C^{*, \text { pre }}\right)-\left(\left(P^{*, \text { post }}-\pi\right)-P^{*, \text { pre }}\right)} .
$$

Intuitively, $I^{*, \text { markup }}$ equals $I^{*, \text { post }}$ if the pre-reform markup equals the post-reform markup. ${ }^{10}$

\subsection{Optimal Tax Penalty}

In addition to using the model to compute welfare impacts, we can also extend our framework to compute policy parameters that results in the social optimum. This simply amounts to recovering the penalty that results in a level of coverage where the pre-reform demand curve intersects the marginal cost curve. This level is depicted in Figure 4 as coverage level $I^{*, o p t}$. Increasing the penalty improves welfare as long as marginal enrollees have a willingness-to-pay in excess of their marginal cost of coverage. Of course, a penalty can be too big in the sense that it is welfare reducing beyond a point. Figure 4 demonstrates such a case. Post-reform insurance coverage exceeds optimal insurance coverage, leading to a welfare loss for some segment of the covered

\footnotetext{
${ }^{10}$ We derive equation 4 in Section A.5 in the online appendix.
} 
population. Specifically, consumers who are located on the pre-reform demand curve between the points $\mathrm{X}$ and $\mathrm{C}$ are not willing to buy health insurance at the marginal cost of covering them. Therefore, their purchase decision decreases social welfare such that the full welfare effect of the mandate is given by the light gray area minus the dark gray area. We show in Section A.6 of the online appendix that the size of the full welfare effect is given by equation 2 .

To calculate the optimal tax penalty, first, we solve for the socially optimal coverage level, $I^{*, \text { opt }}$, in terms of the same set of sufficient statistics from above. We can express the optimal insurance coverage as follows:

$$
\begin{aligned}
I^{*, \text { opt }} & =\max \left(0, \min \left(1, I^{*, \text { pre }}+\frac{\left(P^{*, \text { pre }}-M C^{*, \text { pre }}\right) *\left(I^{*, \text { post }}-I^{*, \text { pre }}\right)}{2\left(A C^{*, \text { post }}-A C^{*, \text { pre }}\right)-\left(\left(P^{*, \text { post }}-\pi\right)-P^{*, \text { pre }}\right)}\right)\right) \\
& =\max \left(0, \min \left(1, I^{*, \text { pre }}+\frac{\left(P^{*, \text { pre }}-A C^{*, \text { pre }}\right) *\left(I^{*, \text { post }}-I^{*, \text { pre }}\right)}{2\left(A C^{*, \text { post }}-A C^{*, \text { pre }}\right)-\left(\left(P^{*, \text { post }}-\pi\right)-P^{*, \text { pre }}\right)}\right.\right. \\
& \left.\left.-\frac{\left(A C^{*, \text { post }}-A C^{*, \text { pre }}\right) * I^{*, \text { pre }}}{2\left(A C^{*, \text { post }}-A C^{*, \text { pre }}\right)-\left(\left(P^{*, \text { post }}-\pi\right)-P^{*, \text { pre }}\right)}\right)\right) .
\end{aligned}
$$

Here, the minimum and the maximum operator address potential corner solutions at zero coverage and full coverage. For an interior solution, we see from the first equality that the optimal insurance coverage exceeds the pre-reform equilibrium coverage, whenever the pre-reform market price exceeds the costs of the marginal consumer. ${ }^{11}$

Next, we can calculate the optimal tax penalty (conditional upon the observed post-reform markup) which shifts the equilibrium coverage to the optimal coverage level. The optimal tax penalty, $\pi^{*}$, equals:

$$
\begin{aligned}
\pi^{*} & =\left(P^{*, \text { post }}-P^{*, \text { pre }}\right)-\left(A C^{*, \text { post }}-A C^{*, \text { pre }}\right) \\
& +\frac{\left(A C^{*, \text { post }}-A C^{*, \text { pre }}\right)-\left(\left(P^{*, \text { post }}-\pi\right)-P^{*, \text { pre }}\right)}{\left(I^{*, \text { post }}-I^{*, \text { pre }}\right)} *\left(I^{*, \text { opt }}-I^{*, \text { pre }}\right) .
\end{aligned}
$$

Intuitively, the optimal tax penalty increases proportionally as the difference between optimal coverage and pre-reform coverage increases.

\footnotetext{
${ }^{11}$ We derive equation 5 in Section A.7 in the online appendix.
} 
Figure 4: Adverse Selection And The Optimal Tax Penalty

\section{Premium}

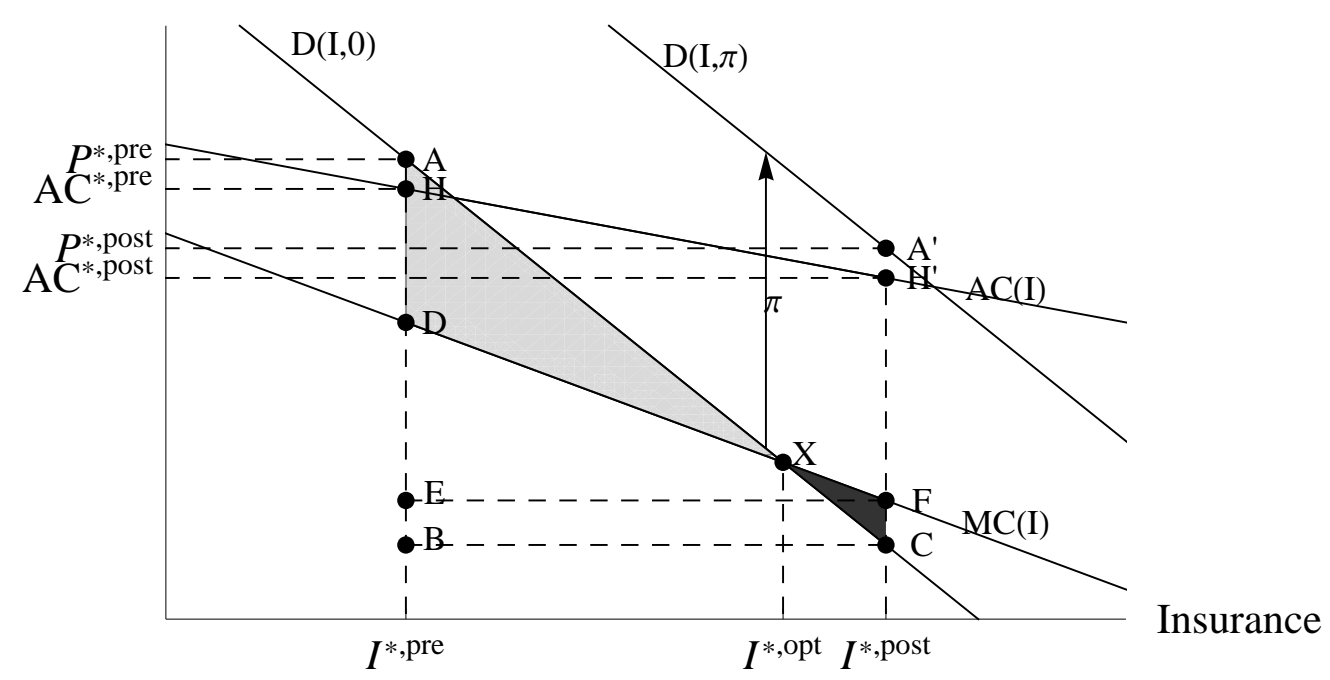

\section{Empirical Model}

We next turn to developing a simple empirical model to estimate the sufficient statistics of the model. While we simply read the pre-reform levels from the data using the average realizations in the pre-reform years 2004 and 2005, we estimate changes in coverage, premiums, and average costs. One important advantage of our approach is the ability to incorporate changes in the remainder of the country to control for trends in these measures unrelated to Massachusetts reform, which may have shifted the demand and average cost curve. The empirical approach follows directly from our theory that demonstrates changes in these variables following health reform. Our primary estimating equation is as follows:

$$
\begin{aligned}
Y_{s t}^{k} & =\gamma^{k} *(M A * \text { After })_{s t}+\rho_{1}^{k} *(M A * \text { During })_{s t}+\rho_{2}^{k} * M A_{s} \\
& +\rho_{3}^{k} * \text { After }_{t}+\rho_{4}^{k} * \text { During }_{t} \\
& +\rho_{5}^{k} *(M A * \text { After } * \text { Year })_{s t}+\rho_{6}^{k} *(M A * \text { During } * \text { Year })_{s t}+\rho_{7}^{k} *(M A * Y \text { ear })_{s t} \\
& +\rho_{8}^{k} *(\text { After } * \text { Year })_{t}+\rho_{9}^{k} *(\text { During } * \text { Year })_{t}+\rho_{10}^{k} * \text { Year }_{t}+\rho_{11}^{k}+\varepsilon_{s t}^{k},
\end{aligned}
$$

where $Y_{s t}^{k}$ denotes the respective outcome measure for state $s$ in year $t$. Specifically, $k$ is either coverage, premiums, or average costs. $M A$ is a dummy variable that equals one for Massachusetts. 
During and After are dummy variables that equal one for the reform years 2006 and 2007, and the post-reform years 2008-2011, respectively. We also include different annual time trends for Massachusetts and the control states, by period, to control more flexibly for reform-unrelated state-specific trends in health care costs. The key parameters of interest are $\gamma^{k}$, which denote the reform's impact on coverage, premiums, and average health claim expenditures. ${ }^{12}$

To estimate the full change in welfare, the net change in welfare, the optimal penalty, and the optimal amount of coverage, we first simply substitute the changes in coverage, premiums, and average health claim expenditures between the pre-reform and the post-reform period with the respective $\gamma^{k}$ estimate in equations 2, 3, 4, and 5. Second, we insert the observed pre-reform levels from the data using the average realization in the pre-reform years 2004 and 2005. Finally, we calibrate the level of the tax penalty, which allows us to calculate the change in welfare according to equation 2. We use an annual tax penalty of $\$ 1,250$ in our baseline specification and consider different values in additional robustness checks. According to Table 1, the average tax penalty is potentially smaller, but equation 2 shows that the overall welfare effects decreases in the calibrated tax penalty. Therefore, our baseline specification describes a conservative welfare estimate with respect to the tax penalty.

\section{Data}

One advantage of our methodology — deriving a small set of sufficient statistics from theory with clear empirical corollaries - is that we are able to model welfare using relatively easy to obtain data. To estimate the sufficient statistics for our empirical analysis, we require data on coverage, premiums, and cost. To support our primary analysis, we obtain data on enrollment, premiums, and cost from the SNL Financial database. We add coverage information from NHIS to express the enrollment information in percentages.

SNL Financial is a leading financial information firm that collects and prepares corporate, fi-

\footnotetext{
${ }^{12}$ Notice that our empirical approach is analogous to estimating the structural equations, the demand curve and the average cost curve, using instrumental variables. For instance, suppose we are only interested in the demand curve and use Massachusetts health reform as an exogenous price shifter. Then, our empirical model nests the first stage if we define premiums as the dependent variable. Second, our empirical model nests the reduced form structural equation as well if we define coverage as the left hand side variable. In other words, if we estimate the empirical model for coverage and premiums separately and compute the ratio of our key parameter estimates, $\frac{\gamma^{P}}{\gamma^{I}}$, then we have identified the slope of the demand curve.
} 
nancial, market, and M\&A data for a variety of different industries, including the health insurance industry. The data set we use is based on data from the National Association of Insurance Commissioners, subsequently aggregated by SNL. Our SNL data span the years 2004-2011 and provide information on enrollment in member-months, revenues, and claim expenditures for US health insurers at the firm-market-year-level. The SNL market definition distinguishes between the group and the non-group (individual) market within each state. While the group market data do not include self-insured plans offered by large employers, the data on the individual market should represent the universe of plans and enrollment on the individual market, which is the focus of our analysis. ${ }^{13}$

For our baseline analysis, we drop insurers in the Massachusetts individual market that offer Commonwealth Care health plans. ${ }^{14}$ The Commonwealth Care program is administered by the Connector and offers highly subsidized access to health insurance for individuals that earn up to $300 \%$ of the FPL. ${ }^{15}$ This subsidy is conceptually equivalent to the tax penalty as both instruments lower the choice-relevant premium. However, our empirical strategy uses data aggregated at the insurer-year level. Therefore, we can not address price variation within a plan unless we impose additional assumptions. We discuss these assumptions in Section 6.1, but for our baseline analysis we drop these insurers to ensure a homogeneous consumer population that does not qualify for subsidies and faces the maximum penalty, assuming that most of these individuals earn more than $300 \%$ of the federal poverty line, see Table 1.

We compute member-month premiums by dividing reported revenues by enrollment in membermonths. Similarly, we derive member-month health claim expenditures using the reported annual expenditures. We multiply these measures by 12 to annualize the premium and the health expenditure estimates. We drop insurer-year observations with premiums or health expenditures that are smaller than $\$ 50$ or larger than $\$ 20,000 .{ }^{16}$ Finally, we normalize all financial variables to 2012 dol-

\footnotetext{
${ }^{13}$ One exception are life insurers, to the extent that they also sell health insurance plans in the individual market, who do not file these reports, see Abraham et al. (2013).

${ }^{14}$ Following the description from the regulator, we drop Boston Medical Center Health net Plan, CeltiCare Health Plan, Fallon Community Health Plan, Neighborhood Health Plan, and Network Health,see http://tinyurl.com/ p92cdx.

${ }^{15}$ For instance, between July 2012 and June 2013 the premiums per member month range from $\$ 40$ for individuals with incomes between $150 \%$ and $200 \%$ of the FPL to $\$ 182$ per member month for individuals with incomes between $250 \%$ and $300 \%$ (https://www.mahealthconnector.org/. Accessed February 1st, 2013.)

${ }^{16}$ This reduces the number of observations by about $8 \%$ in the individual market. We also revise the enrollment information of one provider in New York for the year of 2008 and we drop an insurer in the state of Washington because the provided information seemed unreasonable. These adjustments do not affect our baseline estimates.
} 
lars using the Medical Consumer Price Index. The sample data provide information on 40 firm-year observations in Massachusetts and 1,663 firm-year observations for other states.

We complement the SNL information with restricted-access NHIS data with state identifiers from years 2004-2010. We primarily use these data to translate the enrollment measures from the SNL data, which is reported in levels, into coverage percentages inside and outside of Massachusetts. We make this conversion using the representative population weights. We use the NHIS rather than the SNL to determine the percentage of individuals insured in the individual health insurance market because those data include insured as well as uninsured individuals, while the SNL data only include insured individuals. In addition to detailed data on health insurance coverage, the NHIS also collects demographic information, which allows us to distinguish between the individual and the group markets in our empirical analysis. To match the SNL sample population, we restrict the NHIS sample population to non-elderly adult family members aged 18-64 and drop families that earned less than $300 \%$ of the family-size adjusted federal poverty line. ${ }^{17}$ We also drop family members that were enrolled in a public insurance plan. ${ }^{18}$ We classify family members as participating in the individual market whenever no members of the family are offered health insurance through their respective employer(s). ${ }^{19}$ Having made all of the adjustments mentioned above, we are left with 119,500 family member observations in the group market and 17,500 family member observations in the individual market. ${ }^{20}$ We aggregate these observations to the family level and consider the observation (family) to be uninsured whenever none of the remaining family members has health insurance. Finally, we compute average enrollment at the state-year-market level using representative population weights. As mentioned earlier, Figure 1 presents the respective coverage trends for Massachusetts and the control states.

To compute coverage in percentages, we normalize the average observed post-reform enrollment in the SNL data for the years 2007-2010 to the average observed (state-specific) post-reform cover-

However, they would add noise to our estimates in the robustness check section, where we reduce the analysis to states that have guaranteed issue regulations in place. The data appendix provides additional information on these observations.

${ }^{17}$ The NHIS uses the poverty thresholds from the Census Bureau, which are not identical but very similar to the poverty thresholds for Medicaid and discount eligibility in Massachusetts. We keep children because we also use out-of-pocket spending information in a robustness check, which is reported at the family level.

${ }^{18}$ These public plans include Medicare, Indian Health services, SCHIP, Military health coverage, Medicaid and other state- or government-sponsored plans.

${ }^{19}$ The NHIS asks all adult family members that are present at the time of the interview whether they are offered health insurance though their workplace. For adult persons that are not present during the interview, the NHIS gathers the respective information through a present adult family member.

${ }^{20}$ In Massachusetts, we observe 3,070 family members in the group market and 320 in the individual market. 
age in the NHIS data for the same time period. Using this normalization, we calculate insurance coverage in percentages for all years using the SNL enrollment estimates. We find post-reform coverage levels in the individual market of $92 \%$ in Massachusetts and about $67 \%$ at the national level, see Figure 1. It is worth emphasizing that our sample population in Massachusetts did not achieve universal coverage in the post-reform period. Therefore, we interpret the post-reform equilibrium as an interior solution and assume that the marginal consumer is indifferent between buying and not buying health insurance. Near-universal coverage simplifies the analysis considerably relative to the case of universal coverage. In the latter case, it might be that all consumers strictly prefer health insurance, such that premiums do not necessarily reflect the willingness to pay of the marginal consumer. Because of the small sample size in the NHIS data, we may considerably overestimate or underestimate the post-reform coverage for at least some states. While we can not test whether we underestimate the coverage levels in the post-reform years, we know that we have overestimated the coverage levels if we conclude state-specific coverage estimates of more than $100 \%$ in the pre-reform years. In these circumstances, we normalize the state-specific enrollment trends relative to the highest highest observed enrollment estimate for this particular state. That is, we assume that this state reaches universal coverage in the given year.

While our sample selection reduces the number of observations in the SNL data, and similarly in the NHIS data, it allows us to quantify the effects of the mandate in the individual market for the non-poor population. The restriction to the non-poor population in the individual market is interesting for three key reasons. First, we see the largest changes in private health insurance coverage following health reform in the Massachusetts individual market, rather than in the group market where the employer served as an effective pooling mechanism prior to reform, see Figure 1. Second, the individual market is more likely to be adversely selected than the group market prior to the reform because individual market consumers internalize the full cost of the health plan premium, while group consumers choose from a set of employer sponsored and subsidized health plans. Third, it is important to focus on the non-poor population because individuals that earn less than $300 \%$ of the federal poverty line gained access to highly subsidized health insurance through the Medicaid expansion or the newly introduced Commonwealth Care plans. These programs introduce price variation amongst consumers that is difficult to address using data at the insurer level. Furthermore, crowd-out of private coverage, as has been found in Medicaid expansions 
(e.g. Cutler and Gruber (1996)), would bias our price elasticity estimates (and welfare estimates) downwards if left unaddressed..$^{21}$

\section{Adverse Selection and an Individual Mandate in Practice}

In this section, we discuss our empirical results. We provide graphical and regression-based results that demonstrate the impact of health reform on coverage, premiums, and average costs and quantify the sufficient statistics for our welfare analysis. The regression results, presented in Table 2, correspond to the model in equation 7 for each dependent variable of interest.

We begin by studying the impact of reform on coverage rates. Figure 5 presents coverage trends in the individual market using the normalized SNL data, normalized by coverage rates in the NHIS as described above. The vertical lines separate the pre-reform and the after-reform years. We compare the coverage trends in Massachusetts to an average for states other than Massachusetts, weighted by the annual enrollment in the individual market at the state-year level. Consistent with our findings in the NHIS data (Figure 1) we observe a pronounced increase in coverage in Massachusetts following health reform. At the same time, we do not observe a trend break following reform at the national level.

Table 2 presents the corresponding regression results in column 1. The coefficient $\gamma^{k}$ presented in the first row captures the impact of the reform. The estimate in the first column implies that enrollment in the individual market increased by 19.4 percentage points. This is both statistically and economically significant. ${ }^{22}$ As shown in the bottom row of the table, pre-reform enrollment in the Massachusetts individual market equaled $70.3 \%$ (49,000 annual contracts) such that the estimated impact on enrollment corresponds to an increase of 13,500 annual contracts. These estimates are generally consistent with the reported trends by the Division of Health Care Finance and Policy (DHCFP), supporting the validity of the SNL data. ${ }^{23}$

\footnotetext{
${ }^{21}$ In theory, the Medicaid expansion can also crowd-in private coverage if the expansion targets the unhealthy population (see Clemens (2013)). We think that our estimates would still be biased downwards in this case because of a healthier risk pool of privately insured consumers.

${ }^{22}$ We use a block bootstrap method to calculate the confidence intervals. We discuss this method in the online appendix section B.

${ }^{23}$ The DHCFP reports that enrollment in the individual market increased from 38k in June 2006, individual purchase only, to $71 \mathrm{k}$ in March 2011, see www.mass.gov/chia/docs/r/pubs/12/2011-june-key-indicators.pdf. There are at least two reasons for why the estimates from the DHCFP suggest a larger increase in enrollment. First, the DHCFP measures enrollment in persons whereas we measure enrollment in member months. Since we divide our observed member month estimates by 12, our results will likely understate enrollment measured in the DHCFP.
} 


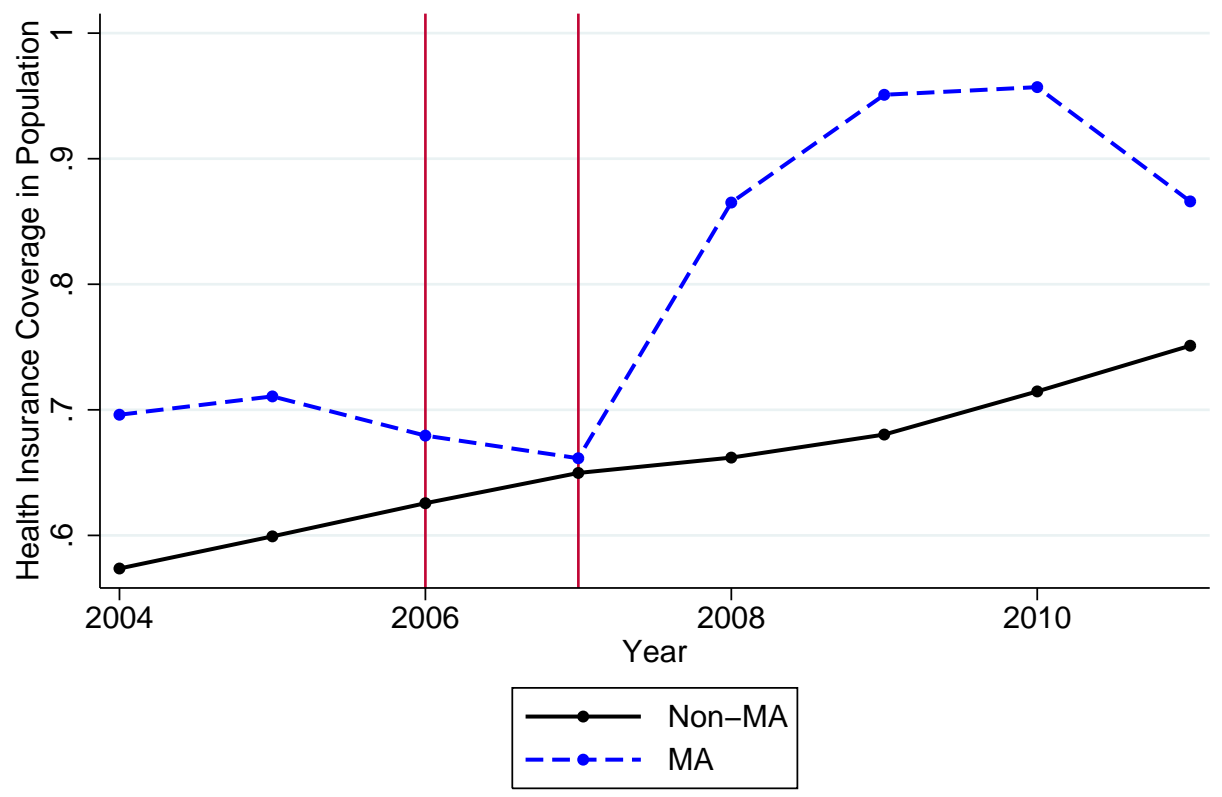

Turning next to the impact on premiums, Figure 6 shows trends in annual premiums per person in the individual market. It is immediately clear that premiums are higher in Massachusetts than they are in other states before reform. While there are various potential explanations for the general differences in health care costs between states, guaranteed issue and community rating regulations are likely to explain the relatively larger cost differences in the individual market, at least in part. In the absence of an individual mandate, we expect that these regulations may lead to an adversely selected pool of insured individuals and the associated high premiums. Supporting this, we find that insurers located in other states that also had guaranteed issue and community rating regulation in place, henceforth "guaranteed issue states", had higher premiums and claim expenditures than the national average. We come back to this comparison in the robustness check section, where we contrast premium and health expenditure trends in Massachusetts with trends in guaranteed issue states.

While the medical-CPI-adjusted premiums remain constant at the national level, we observe a Second, we drop insurers that offer Commonwealth Care plans which are included in the DHCFP estimates. 
Table 2: Regression Results

\begin{tabular}{|c|c|c|c|}
\hline & $\begin{array}{c}(1) \\
\text { Coverage }\end{array}$ & $\begin{array}{c}(2) \\
\text { Premium }\end{array}$ & $\begin{array}{c}(3) \\
\text { Claim Exp }\end{array}$ \\
\hline \multirow{2}{*}{$\gamma^{k}$ MA*After $^{*}$} & $0.194^{* * *}$ & $-1143.0^{* * *}$ & $-621.4^{* * *}$ \\
\hline & {$[0.104,0.279]$} & {$[-1429.1,-691.9]$} & {$[-864.4,-271.4]$} \\
\hline \multirow[t]{2}{*}{$\rho_{1}^{k} \quad \mathrm{MA}^{*}$ During } & $-0.078^{*}$ & 41.2 & -271.4 \\
\hline & {$[-0.156,0.010]$} & {$[-237.5,479.3]$} & {$[-515.9,65.9]$} \\
\hline \multirow[t]{2}{*}{$\rho_{2}^{k} \mathrm{MA}$} & $0.089^{* *}$ & $3536.7^{* * *}$ & $4258.7^{* * *}$ \\
\hline & {$[0.002,0.177]$} & {$[3082.8,3838.6]$} & {$[3906.6,4529.7]$} \\
\hline \multirow[t]{2}{*}{$\rho_{3}^{k}$ After } & -0.024 & -186.7 & 197.9 \\
\hline & {$[-0.110,0.063]$} & {$[-637.8,99.4]$} & {$[-152.1,441.0]$} \\
\hline \multirow{2}{*}{$\rho_{4}^{k}$ During } & -0.001 & $-265.9^{*}$ & 124.4 \\
\hline & {$[-0.088,0.079]$} & {$[-704.1,12.8]$} & {$[-212.9,368.9]$} \\
\hline \multirow[t]{2}{*}{$\rho_{5}^{k} \quad$ MA*After*Year $^{*}$} & -0.018 & -61.8 & $-443.9^{* * *}$ \\
\hline & {$[-0.058,0.024]$} & {$[-203.0,138.6]$} & {$[-560.0,-292.8]$} \\
\hline \multirow{2}{*}{$\rho_{6}^{k} \quad \mathrm{MA}^{*}$ During*${ }^{*}$ Year } & -0.031 & -144.5 & -117.8 \\
\hline & {$[-0.078,0.017]$} & {$[-302.4,91.6]$} & {$[-224.9,49.0]$} \\
\hline \multirow[t]{2}{*}{$\rho_{7}^{k} \quad \mathrm{MA}^{*}$ Year } & -0.011 & 152.0 & $477.8^{* * *}$ \\
\hline & {$[-0.055,0.026]$} & {$[-50.3,281.2]$} & {$[328.4,583.1]$} \\
\hline \multirow[t]{2}{*}{$\rho_{8}^{k} \quad$ After*Year } & 0.005 & $-127.1^{*}$ & 13.0 \\
\hline & {$[-0.038,0.044]$} & {$[-327.5,14.1]$} & {$[-138.0,129.1]$} \\
\hline \multirow[t]{2}{*}{$\rho_{9}^{k} \quad$ During*Year } & -0.001 & $-166.7^{* *}$ & 64.7 \\
\hline & {$[-0.050,0.045]$} & {$[-402.8,-8.8]$} & {$[-102.2,171.7]$} \\
\hline \multirow[t]{2}{*}{$\rho_{10}^{k}$ Year } & 0.026 & 111.8 & -32.3 \\
\hline & {$[-0.012,0.070]$} & {$[-17.4,314.1]$} & {$[-137.7,117.0]$} \\
\hline \multirow[t]{2}{*}{$\rho_{11}^{k}$ Constant } & $0.650^{* * *}$ & $2994.1^{* * *}$ & $2125.5^{\text {*** }}$ \\
\hline & {$[0.568,0.731]$} & {$[2692.3,3448.0]$} & {$[1854.5,2477.6]$} \\
\hline \multicolumn{2}{|l|}{$Y^{*, \text { pre }}$ Pre-Reform Value } & 5871.3 & 5270.6 \\
\hline
\end{tabular}

distinct trend break in Massachusetts following the implementation of health care reform. We see that premiums in Massachusetts adjust to a smaller post-reform level both by changing the rate of growth and by shifting downward in level. Both of these effects are consistent with an initially adversely selected market, where the influx of relatively healthy and inexpensive individuals after reform reduces the average insurer spending per enrollee and thereby reduces the health plan premium charged by the insurers.

Column 2 in Table 2 quantifies the reform's effect on premiums. Our results suggest that premiums in Massachusetts fell by $\$ 1,143$ (19.5\%) following health care reform relative to their pre-reform level of $\$ 5,870$, relative to other states. This estimate is in the same range as that found by Graves and Gruber (2012), who use data collected by the Association for Health Insurance Plans (AHIP). ${ }^{24}$

\footnotetext{
${ }^{24}$ The authors find that between 2006 and 2009, family plans and single plans decreased by $52.3 \%$ and $35.3 \%$ relative
} 


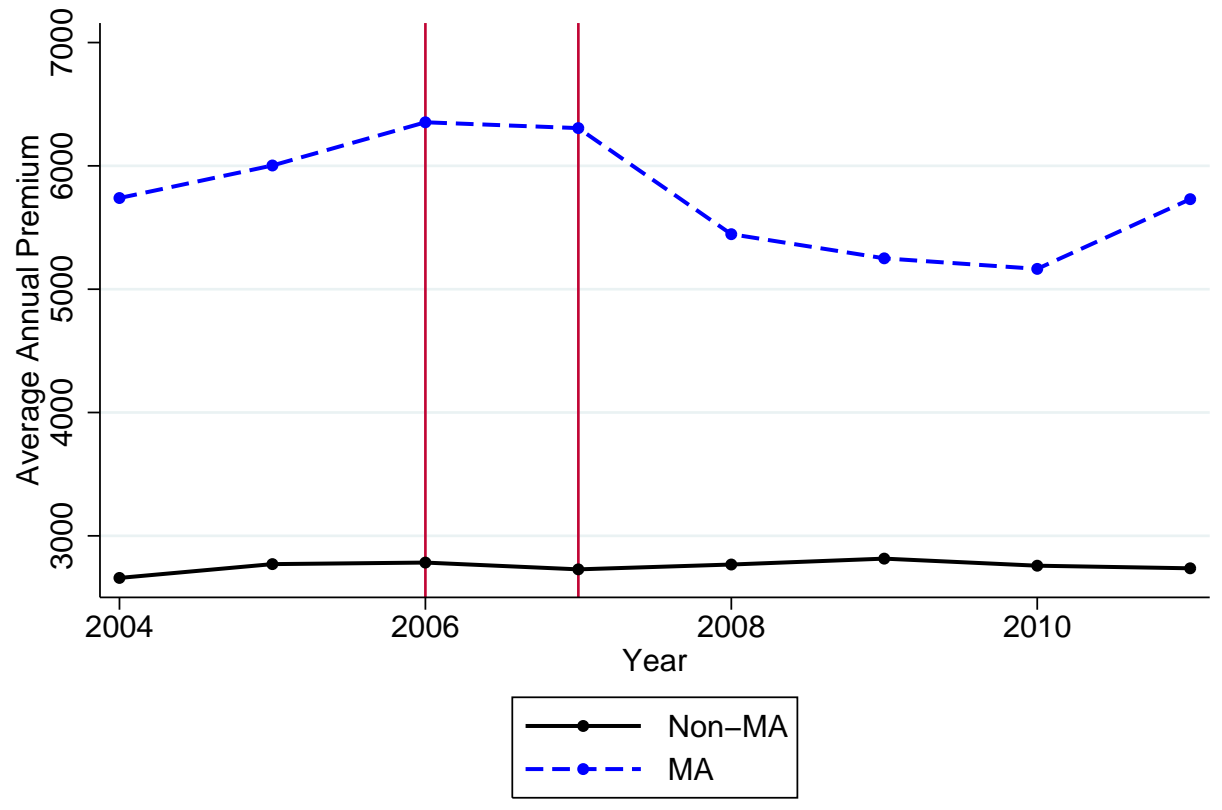

Finally, we turn to the impact of reform on average claims expenditures. Figure 7 presents trends in average claim expenditures in the individual market. Again, the national trend does not suggest any systematic change around the reform period. On the other hand, we observe a noticeable trend break in the Massachusetts individual market. First, we notice a change in the cost growth rate. Average claim expenditures in Massachusetts trend upward prior to the reform even after adjustment for the medical CPI, but remain relatively constant within the post-reform period. Notice that we control for separate pre- and post-reform trends in Massachusetts and at the national level in the regression analysis. Therefore, our key parameter estimate is not affected by this change in the growth rate. Second, we observe a level shift in the year 2007. Intuitively, the post-reform trend in Massachusetts starts off from a smaller level in 2007 relative to what was predicted under the pre-reform trend. This level shift is the actual treatment effect. While we think that the change in the growth rate is also tied to the health reform, we feel more confident that the level shift is attached to changes in the risk pool of the insured individuals because most to the national trend, respectively. We consider the impact of these alternative estimates on welfare in Section 7.6. 
of the change in coverage is realized in the first two post-reform years, as shown in Figure 5.

Figure 7: Annual Average Claim Expenditures

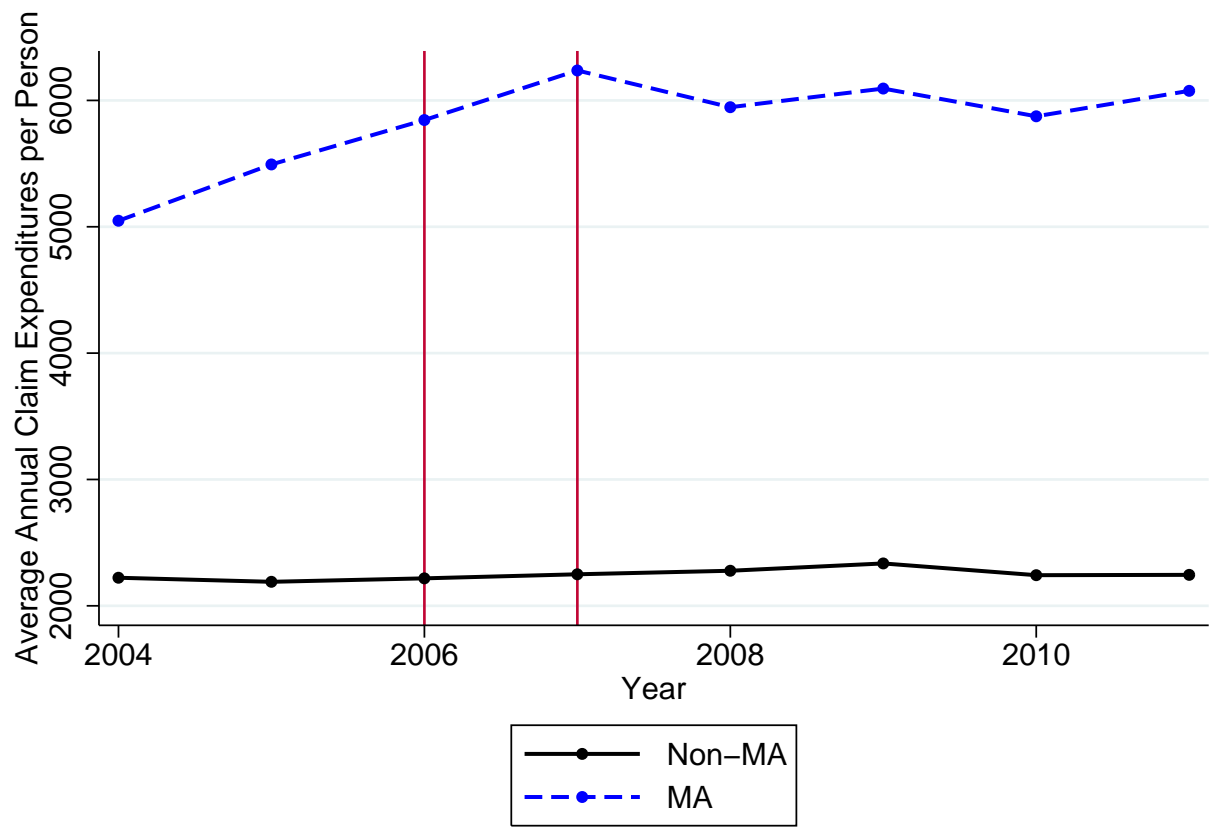

Column 3 in Table 2 quantifies the reform's effect on average claim expenditures, which suggests that they decreased by $\$ 621(12 \%)$ because of the influx of newly insured consumers. Dividing this estimated decrease in average claim expenditures by the underlying change in coverage suggests that the slope of the average cost curve equals $\frac{-\$ 621}{0.194}=-\$ 3,201$. The table also suggests that average claim expenditures equaled $\$ 5,270$ in the pre-reform period, which implies a pre-reform markup of $\$ 600(11 \%)$.

Taken together, the results from the graphical and the regression analysis across the different outcomes of interest suggest that the Massachusetts individual market was adversely selected prior to health reform. As coverage increased, the average expenditure level per enrollee was reduced, as were premiums. This finding is consistent with our earlier findings using data from the hospital market as well and the evidence from the literature (Hackmann et al. (2012); Cutler and Zeckhauser (2000); EFC). On the other hand, we see only minor changes in Massachusetts group market, where 
initial insurance coverage was close to universal levels. This is not particularly surprising for a number of reasons. First, one of the rationales for relying on employer-based insurance is the use of a pooling mechanism unrelated to risk in order to mitigate adverse selection. Further, individuals obtaining coverage through their employer typically do not observe the true cost of their coverage, as this expense is taken out pre-tax and manifests in wage reductions rather than direct premium payments (e.g. Summers (1989)). Consumers in the group market are more likely to purchase health insurance, even in the absence of a mandate, and are less likely to be affected by adverse selection. In light of the evidence on the impact of the reform and the theoretical considerations, our empirical objective is to quantify the welfare gains of the individual mandate in the individual market.

\subsection{Welfare Effects}

Based on our estimates of the key sufficient statistics, we next turn to translating these results into welfare estimates. We do that in two ways. First, we plot the key equilibrium points from our theory using their empirical magnitudes from our estimates. We then use our estimates to compute the change in welfare analytically.

Figure 8 illustrates the empirical average cost curve, the empirical demand curve, and the associated welfare effects graphically. Our findings suggest that the individual mandate increased consumer welfare in the individual market. In fact, we find that the tax penalty could have been even larger to fully internalize the social costs of adverse selection, an observation we return to below. Following the derivation in Section 3.5, we can express the full welfare effect (the light gray and the dark gray area in figure 8) in terms of sufficient statistics that we quantified in the difference-in-differences regression analysis. Specifically, we substitute the estimated pre-reform levels and changes in coverage, premiums, and average costs from Table 2 into equation 2 and find the reform's annual effect on social welfare in Massachusetts:

$$
\begin{aligned}
\Delta W_{\text {full }} & =(\$ 5,871.3-\$ 5,270.6) * 19.4 \% \\
& -(-\$ 621.4) *(70.3 \%+19.4 \%) \\
& +\frac{1}{2}(-\$ 1,143-\$ 1,250) * 19.4 \%=\$ 442 .
\end{aligned}
$$


Figure 8: Adverse Selection And Welfare In Practice

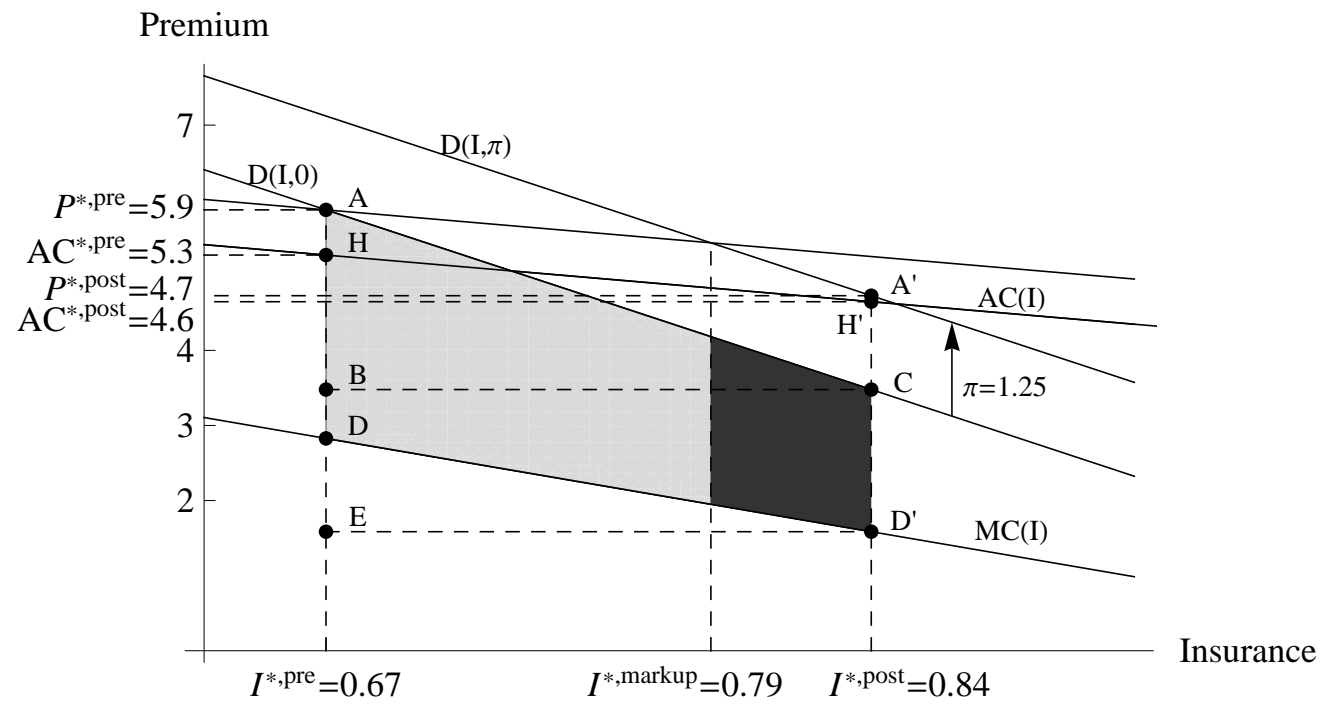

The first term on the right hand side addresses the observed positive pre-reform markup. The second term summarizes the role of the downward sloping average cost curve for our welfare estimates. Intuitively, the size of this effect depends on the change in average costs and the change in coverage but also on the wedge between average and marginal costs in the pre-reform equilibrium, which is why coverage in the pre-reform equilibrium enters the formula. Finally, the third term summarizes the role of changes in premiums for our welfare estimates. A larger decrease in premiums suggests that the newly insured consumers value health insurance by less.

Our model is derived from the perspective of a representative individual. To extrapolate our results to determine overall welfare gains requires us to determine the relevant population. Given the population used in estimation, the estimated welfare gain of $\$ 442$ is per person in the individual market earning more than $300 \%$ of the federal poverty line. For our primary estimates, we assume that individuals above $300 \%$ of the FPL are similar to those receiving full subsidies; marginal costs and the willingness to pay for insurance are independent of an individual's annual earnings. Accordingly, we extrapolate this gain to the universe of individual market participants. We revisit this assumption in the robustness section. To get a population welfare impact, we multiply the per-person estimate by a conservative market size estimate of 212,000 individuals ${ }^{25}$ and find a full

\footnotetext{
${ }^{25}$ To quantify the size of Massachusetts individual market, we first aggregate the reported individual market enrollment in the SNL data across all insurers in Massachusetts at the year level. This includes consumers enrolled in Commonwealth Care plans. Second, we add the uninsured by dividing the aggregate enrollment estimate by our
} 
welfare effect for the entire individual market of $\$ 93.7$ million per year.

To provide further perspective on the magnitude of the welfare estimates, we compare the dollar value of the welfare gain to the average health care cost in the population. From Table 2, the average cost in the population pre-reform was $\$ 5,270$ per year. The total welfare gain of $\$ 442$ is $8.4 \%$ of cost.

To assess the precision of our welfare estimates, we derive the distribution of the welfare effects via bootstrap. The bootstrapped confidence intervals are conditional upon the calibrated tax penalty, which we vary in the robustness section. We describe the details of the bootstrap method in Section B of the online appendix. The first row in Table 3 displays the results for our baseline specification, which suggest that the full welfare effect is statistically significant at the $1 \%$ level, see column 2. We can rule out full welfare gains less than $\$ 162$ and greater than $\$ 646$ with $95 \%$ confidence.

\subsection{Changes In The Markup vs. Adverse Selection}

The full welfare effect combines two effects: the welfare gain from the removal of adverse selection and the welfare gain from a smaller post-reform loading factor. A smaller post-reform markup is consistent with a more competitive market environment in the post-reform period and also with the change in the rating methodology in the individual market, which was carried out in July 2007. One advantage of our empirical method is that we can decompose the full welfare gain into a welfare gain from the removal of adverse selection and a welfare gain from a smaller post-reform markup. Furthermore, we can decompose these effects and assess welfare without modeling the mechanisms for enhanced competition directly, making our framework robust to changes in the market environment that may have affected the conduct of competition. To separately identify the welfare impacts, we compute the welfare gains holding the pre-reform markup constant and attribute this effect to the removal of adverse selection.

Using equation 4, we conclude that health insurance coverage would have increased by 13.7

coverage estimate from the NHIS. Specifically, we calculate average enrollment in the years 2007-2010 and divide the number by our post-reform coverage estimate from the NHIS. Our market size estimate is smaller than the estimate reported by the DHCFP, which suggests that in 2011 about 245,000 individuals were enrolled in the individual market, see rows 2,5 , and 6 in table 2 of the quarterly enrollment update: www.mass.gov/chia/docs $/ \mathrm{r} / \mathrm{pubs} / 12 /$ 2011-june-key-indicators.pdf. As mentioned earlier, this report measures enrollment at the individual level and not at the the member month level. Therefore, the reported enrollment figures overstate our enrollment measure, which is based on 12 member months. 
Table 3: Welfare Effects

\begin{tabular}{lcc}
\hline \hline Tax Penalty & Full Welfare Effect & Net Welfare Effect \\
\hline Baseline: 1250 & $442^{* * *}$ & $335^{* * *}$ \\
& {$[162,646]$} & {$[144,497]$} \\
450 & $520^{* * *}$ & $249^{* * *}$ \\
550 & {$[232,735]$} & {$[123,385]$} \\
& $510^{* * *}$ & $273^{* * *}$ \\
650 & {$[224,724]$} & {$[133,415]$} \\
& $500^{* * *}$ & $291^{* * *}$ \\
750 & {$[216,713]$} & {$[140,439]$} \\
& $491^{* * *}$ & $305^{* * *}$ \\
850 & {$[207,701]$} & {$[144,456]$} \\
& $481^{* * *}$ & $315^{* * *}$ \\
950 & {$[199,691]$} & {$[146,471]$} \\
& $471^{* * *}$ & $323^{* * *}$ \\
1050 & {$[190,679]$} & {$[146,480]$} \\
& $461^{* * *}$ & $329^{* * *}$ \\
1150 & {$[180,669]$} & {$[146,489]$} \\
& $452^{* * *}$ & $333^{* * *}$ \\
1350 & {$[171,657]$} & {$[146,494]$} \\
& $432^{* * *}$ & $336^{* * *}$ \\
\hline GI: 1250 & {$[152,635]$} & {$[140,498]$} \\
& $342^{* * *}$ & $244^{* * *}$ \\
\hline \hline
\end{tabular}

The bootstrapped $95 \%$ confidence interval is displayed in brackets.

${ }^{*} p<0.10,{ }^{* *} p<0.05,{ }^{* * *} p<0.01$

percentage points to $I^{*, \text { markup }}=84 \%$, if the pre-reform load had remained constant. Graphically, $I^{*, \text { markup }}$ refers to the coverage share at which the post-reform demand curve intersects with the pre-reform pricing policy of the insurers. Under the pre-reform markup, premiums and average costs would have decreased by only $\$ 438$. Based on equation 3 , we find that the welfare gains due to the removal of adverse selection, represented by the light gray area, equal $\$ 335$ per individual and year, which is statistically significant at the $1 \%$ level, see column 3 in the first row of Table 3 . From Table 2 , the average cost in the population pre-reform was $\$ 5,270$ per year. Therefore, the welfare gain from the reduction in adverse selection is $6.4 \%$ of total cost. As expected, this gain in the individual health insurance market is larger than the welfare loss from adverse selection that EFC find in their empirical context of the employer sponsored health insurance market of $2.3 \%$ of the maximum money at stake (which is roughly equivalent to our measure of total cost). The welfare gain also exceeds the welfare effects in Einav et al. (2010c), which suggest that adverse selection in the UK annuity market reduces welfare by about $2 \%$ of annuitized wealth. Combined with the market size estimate, the net welfare effect for the entire individual market equals $\$ 71$ million per 
year. This welfare gain seems substantial even relative to the approximately $\$ 800$ million of outlays from the federal government to finance Massachusetts health reform, see McDonough et al. (2006).

The transition to a more competitive market and the change in the premium rating methodology, on the other hand, decreased annual premiums by another $\$ 704$ dollars and the associated welfare gain equals $\$ 107$ per person and $\$ 22.7$ million for the entire market. While both effects enhanced welfare, these estimates suggest that $76 \%$ of the total welfare gains came from reductions in adverse selection.

The relative contribution is of particular interest if one considers a common trade-off in insurance market design. Enhancing competition and choice, generally, requires the introduction of additional plans to the market. These additions can also lead to welfare losses from adverse selection (e.g. Cutler and Zeckhauser (2000)). In our setting, both effects enhanced welfare because reform seems to have enhanced competition and because our model limits the contract space to uninsured or insured. In other settings, however, our methodology would allow for the decomposition of these two effects even if they have the opposite impact on welfare.

\subsection{Optimal Tax Penalty}

Our final application of our methodology is to compute the optimal individual mandate penalty based on our empirical estimates for the key sufficient statistics. As we note above, the demand shift due to the statutory penalty in Massachusetts enhanced welfare. Figure 8, however, demonstrates that a larger shift would have increased welfare even further. Specifically, our empirical results suggest that the social optimum occurs at universal coverage levels, as even the consumers with the lowest willingness would purchase health insurance if it were offered at their marginal costs. We can use our model to compute the smallest tax penalty that implies universal insurance coverage. ${ }^{26}$

In practice, the tax penalty must be sufficiently large such that the consumer with the lowest willingness-to-pay is willing to purchase health insurance if it is offered at average costs of all consumers plus the post-reform markup that insurers charge on top of the realized average costs. Using equation 6 , we conclude that the minimal tax penalty that implements universal coverage levels equals $\$ 2,190$. While this optimal penalty exceeds the actual penalty in Massachusetts, is does resemble the proposed penalty for national reform, which can equal the maximum of $\$ 2,085$

\footnotetext{
${ }^{26}$ In order to quantify the socially optimal penalty, we assume that the post-reform markup remains unchanged if we vary the magnitude of the tax penalty.
} 
and $2.5 \%$ of household income.

\section{Robustness}

In this section, we first conduct a sensitivity analysis of our welfare estimates with respect to the tax penalty. Next, we contrast the trends in Massachusetts individual market with other states that also had guaranteed issue regulations as well as community rating laws in place. We continue with a more careful analysis of the community rating regulations in Massachusetts and investigate whether they affect our empirical estimates. Next, we test whether there have been meaningful changes in the generosity of the offered health insurance plans. We then revisit the welfare gains for the entire individual market using reported average costs of all insurers in Massachusetts individual market. Finally, we compare our regression results to other findings in the literature and investigate the implications for social welfare.

\subsection{The Role of the Penalty}

Because we have calibrated the penalty, we assess the robustness of our welfare results to alternative penalty amounts. ${ }^{27}$ Equation 2 shows that as the penalty decreases, there is a linear increase in the change in welfare. Since our baseline penalty constitutes an upper bound for the actual tax penalty, see Table 1, our baseline estimate provides a conservative estimate for the full welfare effect. For instance, the full welfare effect increases by $\$ 9.7$ per person if the underlying changes in coverage stem from a $\$ 100$ smaller tax penalty. ${ }^{28}$ Graphically, a smaller tax penalty shifts point $\mathrm{C}$ in the direction of point A', see Figure 8. The effect of the tax penalty on the welfare estimate is linear because the width of the shaded polygon, $I^{*, p o s t}-I^{*}$,pre , remains unchanged. Column 2 of Table 3 summarizes the respective full welfare estimates for different calibrated tax penalties. The estimates do not differ meaningfully from our baseline estimate of $\$ 442$, varying from $\$ 432$ at a penalty of $\$ 1,350$ to $\$ 520$ at a penalty of $\$ 450$. Therefore, the calibration of the penalty does not seem to have a large impact on our estimated full welfare effects.

The effect of the tax penalty on the net welfare effect is ambiguous. While a smaller tax penalty

\footnotetext{
${ }^{27}$ This robustness exercise also addresses differences between the actual tax penalty and the perceived tax penalty, see e.g. Ericson and Kessler (2013) who investigate counterfactual demand responses to the mandate had it been articulated as a tax on the uninsured.

$28 \frac{I^{*, p o s t}-I^{*, p r e}=19.4 \%}{2} * \$ 100$
} 
still implies a more elastic market demand function, a smaller tax penalty also implies a smaller post-reform coverage level in the absence of changes in insurer markups. Column 3 of Table 3 summarizes the welfare effects associated with the removal of adverse selection for different tax penalties. These welfare effects are hump-shaped and peak at a penalty of $\$ 1,407$. While the net welfare effects vary with the underlying penalty, we think that the relevant support for the underlying penalty lies between $\$ 950$ and $\$ 1,250$ given our restrictive sample selection. Therefore, the net welfare effect ranges between $\$ 323$ and $\$ 336$ per individual and year. Again, the calibration of the penalty seems to have a very small impact on our estimated net welfare effects.

\subsection{Comparison to Guaranteed Issue States}

Our main empirical specification compares trends in the Massachusetts individual market to trends in the individual market of other states. If pre-reform regulations led to different trends in the individual market across states, then we might better control for trends by comparing Massachusetts to other states with similar pre-reform regulations. Only five states - Maine, Massachusetts, New York, Vermont, and Washington - had comparable guaranteed issue regulations combined with community rating laws in place. ${ }^{29}$ If these states experience common time trends that differ from those observed in other US states, then our baseline point estimates confound the effects of health reform with general time trends that are unrelated to health reform.

To test for differences in time trends between guaranteed issue states and other states, we estimate an augmented specification that adds separate time trends and a separate fixed effect for guaranteed issue states, see Table $4 .{ }^{30}$ We are primarily interested in the partial effect of the guaranteed-issue-post-reform interaction term, $G I *$ After, which captures common trends around the reform period amongst guaranteed issue states. Our findings suggest that the trends differ slightly between guaranteed issue states and the remaining states. These parameter estimates are not statistically significant, but they suggest that guaranteed issue states experienced a small increase in coverage combined with an increase in the annual premium and a decrease in average

\footnotetext{
${ }^{29}$ Kentucky and New Hampshire enacted similar regulations in 1994 but repealed the laws in 2000 and 2002 respectively, see Wachenheim and Leida (2012). New Jersey passed similar regulations in 1992 as well but we dropped the state from this small control group since it passed a legislation in 2008, which aimed at coverage expansion. Among other aspects, this legislation mandated coverage for children and expanded coverage for lowincome parents. Furthermore, the law included several reforms to the small group and in the individual market, see Wachenheim and Leida (2012). Therefore, it remains unclear whether New Jersey constitutes a control state or a treatment state in our empirical framework.

${ }^{30}$ We also report the relevant trend graphs in the online appendix, Section A.9.
} 
annual claim expenditures. While each of these effects is relatively small, they all suggest that our baseline effects may slightly overstate the full welfare effect. First, the slight increase in coverage suggests that the reform's effect on coverage was slightly smaller, which lowers the welfare effect. Second, the increase in premiums suggests that premiums in Massachusetts decreased by even more. Combined with a smaller response in coverage, we conclude that demand is potentially less elastic, meaning that the willingness to pay of the newly insured consumers is smaller. Third, the small decrease in average claim expenditures in the guaranteed issue states suggests that adverse selection was less prevalent prior to reform, which also lowers the welfare effect.

Following the outlined steps in Section 6, we revisit the welfare effects using the parameter estimates from the first row in Table 3. The results in the last row of Table 3 confirm our intuition

- they suggest a smaller full welfare effect of $\$ 342$, which combines a net effect of $\$ 244$ and a welfare gain from a smaller post-reform loading factor of $\$ 98$. The revised welfare effects fall short of our baseline results by about $25 \%$, but they are still within the $95 \%$ confidence interval on our main estimate, and they are still statistically different from zero at the $1 \%$ level.

\subsection{Community Rating}

Our baseline model assumes perfect community rating such that premiums may not vary in observable consumer characteristics. In reality, premiums may vary across ages but only up to a factor of two. While this regulation is not as stringent as our baseline assumption, the community rating regulation is still binding as expected health expenditures vary considerably across ages. To quantify age-related differences in health expenditures we use data from the Medical Expenditure Panel Survey (MEPS). We use data from 2004-2010 from all states and sum expenditures on emergency room visits, inpatient and outpatient stays, prescription drugs, and other expenditures at the individual-year level. We use the Medical Consumer Price Index to normalize the average health expenditures to 2012 prices. Finally, we estimate conditional means for the non-elderly adult population aged 18-65 using a standard nonparametric kernel estimator and find that health expenditures vary by up to factor of 6 across ages.

Even though the community rating regulations appear to be binding, insurers may still, at least to some extent, price discriminate against older (more expensive) consumers. This may affect our demand estimates if the average age of the newly insured differs from the average age of the 
Table 4: Augmented Difference-in-Differences Regression Results

\begin{tabular}{|c|c|c|c|}
\hline & $\begin{array}{c}(1) \\
\text { Coverage }\end{array}$ & $\begin{array}{c}(2) \\
\text { Premium }\end{array}$ & $\begin{array}{c}(3) \\
\text { Claim Exp }\end{array}$ \\
\hline \multirow[t]{2}{*}{$\gamma^{k} \mathrm{MA}^{*}$ After } & $0.151^{* *}$ & $-1212.8^{* *}$ & $-511.4^{* *}$ \\
\hline & {$[0.089,0.614]$} & {$[-2013.5,-699.8]$} & {$[-815.3,-306.6]$} \\
\hline \multirow{2}{*}{$\rho_{1}^{k} \quad \mathrm{MA}^{*}$ During } & -0.105 & -58.5 & -189.2 \\
\hline & {$[-0.140,0.080]$} & {$[-1095.5,349.9]$} & {$[-536.8,183.0]$} \\
\hline \multirow[t]{2}{*}{$\rho_{2}^{k} \mathrm{MA}$} & 0.145 & $3186.2^{* * *}$ & $3691.7 * * *$ \\
\hline & {$[-0.158,0.503]$} & {$[2190.9,3991.3]$} & {$[2186.4,4485.2]$} \\
\hline \multirow[t]{2}{*}{$\rho_{3}^{k} \quad$ After } & -0.026 & -224.4 & 180.1 \\
\hline & {$[-0.123,0.072]$} & {$[-739.8,96.0]$} & {$[-177.1,444.8]$} \\
\hline \multirow[t]{2}{*}{$\rho_{4}^{k}$ During } & -0.002 & $-305.2^{*}$ & 104.5 \\
\hline & {$[-0.101,0.086]$} & {$[-805.9,8.4]$} & {$[-248.0,360.9]$} \\
\hline \multirow[t]{2}{*}{$\rho_{5}^{k}$ MA*After*Year } & 0.006 & -244.8 & -493.0 \\
\hline & {$[-0.054,0.024]$} & {$[-719.1,214.3]$} & {$[-645.8,140.3]$} \\
\hline \multirow[t]{2}{*}{$\rho_{6}^{k} \quad$ MA*During*Year } & -0.066 & $-389.5^{* * *}$ & $-155.8^{*}$ \\
\hline & {$[-0.101,0.114]$} & {$[-1198.9,-228.5]$} & {$[-431.3,444.0]$} \\
\hline \multirow[t]{2}{*}{$\rho_{7}^{k} \quad \mathrm{MA}^{*}$ Year } & -0.004 & 271.4 & 507.1 \\
\hline & {$[-0.017,0.030]$} & {$[-48.0,407.7]$} & {$[-33.7,609.8]$} \\
\hline \multirow{2}{*}{$\rho_{8}^{k} \quad$ After*Year } & 0.007 & $-156.8^{* *}$ & -3.5 \\
\hline & {$[-0.040,0.049]$} & {$[-375.2,-11.4]$} & {$[-150.6,112.4]$} \\
\hline \multirow[t]{2}{*}{$\rho_{9}^{k} \quad$ During*Year } & -0.004 & $-205.3^{* *}$ & 46.6 \\
\hline & {$[-0.057,0.046]$} & {$[-455.3,-40.8]$} & {$[-125.6,166.5]$} \\
\hline \multirow[t]{2}{*}{$\rho_{10}^{k}$ Year } & 0.025 & $137.8^{*}$ & -15.9 \\
\hline & {$[-0.017,0.074]$} & {$[-3.3,365.6]$} & {$[-124.4,127.0]$} \\
\hline \multirow[t]{2}{*}{ GI*After } & 0.044 & 107.5 & -92.2 \\
\hline & {$[-0.441,0.164]$} & {$[-558.7,925.4]$} & {$[-462.7,379.3]$} \\
\hline \multirow[t]{2}{*}{ GI*During } & 0.029 & 139.0 & -62.2 \\
\hline & {$[-0.181,0.129]$} & {$[-403.5,1157.2]$} & {$[-479.2,438.0]$} \\
\hline \multirow[t]{2}{*}{ GI } & -0.059 & 354.1 & 593.4 \\
\hline & {$[-0.415,0.258]$} & {$[-655.6,1514.7]$} & {$[-281.6,1902.7]$} \\
\hline \multirow[t]{2}{*}{ GI*After*Year } & -0.027 & 212.7 & 65.6 \\
\hline & {$[-0.071,0.045]$} & {$[-342.2,626.3]$} & {$[-584.3,271.0]$} \\
\hline \multirow[t]{2}{*}{ GI*During*Year } & 0.037 & $283.6^{* *}$ & 56.0 \\
\hline & {$[-0.151,0.098]$} & {$[52.6,1063.8]$} & {$[-402.6,340.0]$} \\
\hline \multirow[t]{2}{*}{ GI*Year } & -0.007 & -145.4 & -45.8 \\
\hline & {$[-0.067,0.036]$} & {$[-425.5,211.6]$} & {$[-209.9,515.6]$} \\
\hline \multirow[t]{2}{*}{$\rho_{11}^{k}$ Constant } & $0.654^{* * *}$ & $2990.5^{* * *}$ & $2099.2^{* * *}$ \\
\hline & {$[0.563,0.741]$} & {$[2649.0,3493.2]$} & {$[1832.0,2485.1]$} \\
\hline \multicolumn{2}{|l|}{$Y^{*, \text { pre }}$ Pre-Reform Value } & 5871.3 & 5270.6 \\
\hline
\end{tabular}


previously insured. For instance, if the newly insured are younger on average, then we overstate the change in the premiums by imposing perfect community rating. Consequently, we would conclude that the demand for health insurance is too inelastic and our welfare estimates would be too conservative. The opposite holds, if the newly insured are older on average.

To test for changes in the age composition in the pool of insured consumers, we revisit changes in the age distribution reported by the DHCFP, see Table $5 .^{31}$ The estimates suggest that the average

Table 5: Average Age in Massachusetts by Market Segment

\begin{tabular}{lcccccc}
\hline \hline & 2005 & 2006 & 2007 & 2008 & 2009 & $2009-2005$ \\
\hline Individual & 36.9 & 36.8 & 37.3 & 37.1 & 37.3 & 0.4 \\
Small Group & 33.1 & 33.3 & 33.5 & 33.7 & 34.1 & 1.0 \\
Mid-Size Group & 32.6 & 33.0 & 33.2 & 33.2 & 33.3 & 0.7 \\
Large Group & 33.3 & 33.4 & 33.7 & 33.7 & 34.8 & 1.5 \\
\hline \hline
\end{tabular}

age of insured consumers in Massachusetts individual market increased by 0.4 years between 2005 and 2009. Our cost estimates would imply that the average age of the insured consumers decreased over the reform period. However, the increase may reflect a reform-unrelated demographic time trend, which is consistent with even larger increases in average age in the other market segments. Unlike our main estimates, these results do not control for national trends because they are based only on Massachusetts data. Nevertheless, we continue our analysis assuming that the increase in age was reform related, which provides a conservative lower bound for our welfare estimates with respect to the role of community rating. Next, we estimate the effect of age on average health expenditures in a simple linear regression model using the MEPS data. We find that a one year increase in age increases total health expenditures by $\$ 93$. Assuming that insurers could perfectly price discriminate based on age, we conclude that premiums vary on average by up to $\$ 93 *$ (Actuarial Value $) *(1+$ Markup $)$ per year of age. To be conservative, we assume that the actuarial value equals $100 \%$ and use the larger pre-reform markup of $11.4 \%$. Hence, we conclude that the average annual premium may have increased by only $\$ 41$ because of the increase in average age of 0.4 years. This effect is negligible compared to our estimated change in the effective premium of $-\$ 1,143-\$ 1,250=-\$ 2,393$. Therefore, we conclude that our welfare estimates are robust with

\footnotetext{
${ }^{31}$ We combine information from the Massachusetts Health Care Cost Trends Final Report 2010, Appendices A.1aA.3b, p.138, and the Massachusetts Health Care Cost Trends, Premium Levels and Trends in Private health Plans: 2007-2009, p.13.
} 
respect to deviations from our perfect community rating assumption.

\subsection{Change in the Generosity of Plan Design}

Our baseline specification abstracts from potential changes in the generosity of health insurance plans. Therefore, our estimates overstate the role of adverse selection if consumers in the Massachusetts individual market purchase relatively less generous health insurance plans following health care reform. To quantify potential changes in plan generosity, we analyze insurer characteristics in the SNL data and information on plan characteristics from the literature.

We begin our discussion with an analysis of the SNL data. The data are aggregated at the insurer-year level, which implies that we can only address differences in plan generosity between insurance carriers. Since the SNL data do not provide explicit information on plan characteristics, we use the insurer name as a proxy for the generosity of the representative (most popular) insurance plan. Specifically, we assume that insurers that carry the word "HMO" in their name offer insurance plans that are on average less generous. Based on this assumption, we calculate the share of insured consumers that are enrolled in HMO plans at the state-year level. In Massachusetts, we find that HMO enrollment trends upward over time, but we do not find a noticeable change in enrollment between 2007 and 2008. ${ }^{32}$ On the other hand, we observe a trend break and a level shift in average costs between 2007 and 2008, see Figure 7. Therefore, we do not think that changes in HMO enrollment can explain the changes in Massachusetts average cost trend. To investigate the role of HMO enrollment for our baseline results in further detail, we re-estimate our empirical specification, see equation 7, controlling for the share of insured consumers that purchase insurance plans from HMO-type insurers at the state-year level. The findings suggest that, holding plan generosity constant, premiums and average costs decrease by $\$ 1,325$ and $\$ 800$ respectively. These estimates are similar to our baseline findings and suggest that if anything, our baseline results understate the welfare gains from the individual mandate. ${ }^{33}$ However, we note that the partial effect of HMO enrollment on premiums and average costs is positive, which suggests that HMO

\footnotetext{
${ }^{32}$ In Massachusetts, we find one HMO insurer. This insurer does not report enrollment in 2004, even though other sources suggest that enrollment for this insurer was similar in 2004 and 2005. Therefore, we assume that HMO enrollment in 2004 equals the observed enrollment in 2005. Otherwise, enrollment would increase from $0 \%$ to $59 \%$ in 2005.

${ }^{33}$ The larger premium drop suggests a less elastic demand curve and a smaller welfare gain. However, the larger decrease in average costs outweighs the larger decrease in premiums such that on net, our baseline results understate the potential welfare gains.
} 
plans are either more generous or attract more costly consumers. Both interpretations are counterintuitive. Nevertheless, the findings from this robustness check do not suggest that changes in plan generosity bias our baseline estimates upwards.

Second, we revisit evidence from the literature on changes in plan generosity. The DHCFP computes the actuarial value of the most popular plan of each carrier in Massachusetts individual market for 2007 and 2008, based on a proprietary pricing model, and reports the actuarial value and other characteristics for the least generous plan, the median plan, and the most generous plan, see Table $6 .{ }^{34}$ The results suggest that the entire distribution shifted between 2007 and 2008 toward slightly more generous insurance plans. On the other hand, the DHCFP also finds that consumer cost sharing increased as a percentage of total expenditures in the individual market from $11.1 \%$ in 2007 to $12.7 \%$ in 2008 . As argued earlier, this can be interpreted as evidence for adverse selection because the newly insured healthy individuals contribute relatively more to their total expenditures in benefit plans with high deductibles. But even if we interpret the increase in consumer cost sharing as evidence for a decrease in plan generosity, despite the evidence on an increase in the actuarial value, then the increase can only account for a small fraction of our baseline welfare estimates. Specifically, we conclude that only $\$ 85(14 \%)$ of the measured decrease in average costs can be explained by a decrease in plan generosity. ${ }^{35}$

Based on the evidence from the SNL data and the literature, we conclude that changes in the plan generosity can at most explain a small fraction of our baseline welfare estimates. In fact, the evidence suggests that our welfare estimates are conservative with respect to potential changes in plan generosity.

\footnotetext{
${ }^{34}$ Unfortunately, we could not find these statistics for earlier years.

${ }^{35}$ Total expenditures per person combine the average costs paid by the insurer, AC, and the consumer's contribution C. Since consumer cost sharing in 2008 equaled $12.7 \%$, we know that

$$
0.127=\frac{C^{*, p o s t}}{A C^{*, p o s t}+C^{*, p o s t}} .
$$

We know that $A C^{*, \text { post }}=\$ 4,650$. Therefore, we can solve for $C^{*, p o s t}$, which equals $\$ 677$. Now we can calculate the post-reform consumer contribution that maintains the pre-reform expenditure share of $11.1 \%$. We conclude that the post-reform cost-sharing ratio equals the pre-reform cost-sharing ratio if the post-reform consumer and insurer expenditures equal $\$ 591$ and $\$ 4,735$ respectively. Hence, our baseline results overestimate the reform's effect on average costs by about $\$ 4,735-\$ 4,650=\$ 85$.
} 
Table 6: Plan Generosity

\begin{tabular}{|c|c|c|c|c|c|c|}
\hline & \multicolumn{3}{|c|}{2007} & \multicolumn{3}{|c|}{2008} \\
\hline & Minimum & Median & Maximum & Minimum & Median & Maximum \\
\hline Actuarial Value & 0.578 & 0.694 & 0.726 & 0.635 & 0.726 & 0.860 \\
\hline Deductible & $\$ 2000$ & $\$ 2000$ & $\$ 2000$ & $\$ 2000$ & $\$ 2000$ & None \\
\hline Coinsurance & $\mathrm{N} / \mathrm{A}$ & $\mathrm{N} / \mathrm{A}$ & $\mathrm{N} / \mathrm{A}$ & $\mathrm{N} / \mathrm{A}$ & $\mathrm{N} / \mathrm{A}$ & $\mathrm{N} / \mathrm{A}$ \\
\hline PCP Office Visit & $\$ 35$ & $\$ 25$ & $\$ 25$ & $\$ 35$ & $\$ 25$ & $\$ 25$ \\
\hline SPC Office Visit & $\$ 50$ & $\$ 25$ & $\$ 25$ & $\$ 50$ & $\$ 25$ & $\$ 25$ \\
\hline Inpatient Copay & Deductible & Deductible & $\$ 500$ & Deductible & $\$ 500$ & $\$ 800$ \\
\hline Outpatient Surgery Copay & Deductible & Deductible & $\$ 250$ & Deductible & $\$ 250$ & $\$ 250$ \\
\hline Emergency Room Copay & $\$ 200$ & $\$ 100$ & $\$ 75$ & $\$ 200$ & $\$ 75$ & $\$ 100$ \\
\hline Pharmacy Deductible & $\mathrm{N} / \mathrm{A}$ & None & None & $\$ 250$ & None & None \\
\hline Retail Generic & $\mathrm{N} / \mathrm{A}$ & $\$ 10$ & $\$ 10$ & $\$ 20$ & $\$ 10$ & $\$ 15$ \\
\hline Retail Preferred & $\mathrm{N} / \mathrm{A}$ & $\$ 50$ & $\$ 30$ & $\$ 50$ & $\$ 30$ & $\$ 30$ \\
\hline Retail Non-Preferred & $\mathrm{N} / \mathrm{A}$ & $\$ 100$ & $\$ 60$ & $\$ 75$ & $\$ 60$ & $\$ 50$ \\
\hline
\end{tabular}

Source: DHCFP Massachusetts Health Care Cost Trends Final Report 2010. Appendices A.1a-A.3b, p.149

\subsection{Welfare Gains For The Entire Individual Market}

In Section 6, we multiplied the per person welfare gains in our sample population by the size of the individual market to predict the welfare gains for the entire individual market. This approach is valid if marginal costs and the slope of the demand curve do not differ across income groups. While we can not recover the demand curve for the entire market from aggregate data, ${ }^{36}$ we revisit variation in costs using data on all insurers in the Massachusetts individual market, including those that offer Commonwealth Care plans. We re-estimate the coverage and the average cost differencein-differences specifications using the entire Massachusetts individual market. Finally, we combine these findings with the demand estimates from Section 6 to compute the welfare effects in this population.

Using the post-reform coverage normalization discussed earlier, we find that the reform increased coverage by 68 percentage points in the full sample. This effect combines the coverage gains in our baseline sample with coverage gains in Commonwealth Care plans. The results from the average cost specification suggest that pre-reform average costs equal $\$ 5,270$ per insured person and that the reform decreased average costs by $\$ 1,755$. Consistent with the larger enrollment gains, the effect on average costs exceeds our baseline results as well. To compare the magnitude of changes

\footnotetext{
${ }^{36}$ This is because consumers face different income-dependent premiums because of the variation in penalties and subsidies, see the discussion in Section 5.
} 
in average costs across samples, we calculate the average costs of the newly insured. ${ }^{37}$ We find that the average costs of the newly insured equal $\$ 2,896$ in the full sample and $\$ 2,397$ in our baseline sample. This suggests that the newly insured individuals in our non-poor baseline population have better health profiles than the new enrollees in the Commonwealth Care plans, who earn less than $300 \%$ of the FPL.

Using the new average cost estimates, we can now revisit the full and the net welfare effects per person. We update the average costs in the post-reform period using a weighted average of the average costs of the previously insured and the newly insured, where the weights reflect the coverage trends in our baseline analysis. Specifically, we find that the average costs in the postreform period for the entire market equal $\$ 4,785$ in the absence of subsidies and variation in the tax penalty. ${ }^{38}$ As mentioned earlier, we assume that the slope of the demand curve does not vary across income groups. Therefore, coverage would have increased by only $19.4 \%$ in the the entire sample, had everybody been exposed to same tax penalty of $\$ 1,250$ and had there been no subsidies for individuals earning less than $300 \%$ of the FPL. Using the new average cost estimates, we find that the full and the net welfare effects per person equal $\$ 345$ and $\$ 259$, respectively. Both effects fall short of our baseline estimates by about $23 \%$, but they are still within the $95 \%$ confidence intervals on our baseline estimates, and they are statistically different from zero at the $5 \%$ level. Multiplied by the predicted market size of 212,000 individuals, we conclude that the full welfare gains for the entire individual market equal $\$ 73.1$ million. The net welfare gains attributed to the removal of adverse selection equal $\$ 54.9$ million.

\subsection{Robustness of Welfare Effects to Estimates from Other Studies}

To assess the sensitivity of our welfare estimates with respect to our sample population, we revisit the welfare results using premium and cost data from other sources in the literature. We begin by considering estimates for premium changes from Graves and Gruber (2012). The authors use

\footnotetext{
${ }^{37}$ For the full sample we solve for the average costs of newly insured $x$ as follows:

$$
\frac{0.24 * \$ 5,270+0.68 * x}{0.24+0.68}=\$ 5270-\$ 1755 .
$$
}

Similarly, we solve for the average costs of newly insured in our baseline sample.

${ }^{38}$ We have

$$
A C^{*, p o s t}=\frac{0.703 * \$ 5,270+0.194 * \$ 2,896}{0.703+0.194}=\$ 4,756
$$


data from the Association for Health Insurance Plans and find that after health reform, premiums in Massachusetts decreased relative to other states by $35 \%$ and $52 \%$ for single plans and family plans respectively. Since the average number of members per contract equals about 1.5 in our time period ${ }^{39}$ we conclude that the trends for single plans are fairly representative for our sample population. Therefore, we adjust our estimate for the impact of health reform and annual premiums from $-\$ 1,143$ to $-\$ 2,055 .{ }^{40}$ Since Graves and Gruber (2012) do not provide information on changes in average costs, we continue with our cost estimates from the SNL data. Based on the premium results, we expect that the authors would find a larger decrease in average costs, relative to our findings, had they explored changes in average costs as well. Therefore, we interpret the revised welfare estimates as a potentially conservative benchmark. Using the new estimate on changes in premiums, we find a full welfare gain of $\$ 353$ and a net welfare gain of $\$ 214$, see the second row of Table 7 . These estimates fall short of our baseline results by $20 \%$ and $36 \%$, which is roughly proportional to the underlying change in the slope of the demand curve. ${ }^{41}$

Table 7: Welfare Gains Using Demand Estimates From the Literature

\begin{tabular}{lcc}
\hline \hline & Full Welfare Effect & Net Welfare Effect \\
\hline Baseline Estimates & 442 & 335 \\
Graves and Gruber (2012) & 353 & 214 \\
Ericson and Starc (2012): Premiums & 555 & 851 \\
Ericson and Starc (2012): Coverage & 444 & 349 \\
Hackmann, Kolstad, and Kowalski (2012) & 453 & 344 \\
\hline \hline
\end{tabular}

Next, we reconsider our welfare estimate using the demand elasticity estimates from Ericson and Starc (2012). The authors use data from the Massachusetts Connector on unsubsidized health insurance purchases in the individual market. Their price elasticities reflect the demand behavior at the intensive margin since the authors do not observe individuals that decide to remain uninsured. In comparison to our demand estimates, we expect that the authors find relatively high price elasticities because plan characteristics vary less at the intensive margin (compared to the extensive margin) and because the connector provides an internet platform that allows consumers to compare premiums amongst plans. We multiply the reported age group specific semi price elasticities by

\footnotetext{
${ }^{39}$ See DHCFP data appendix, page 140

${ }^{40} 35 \%$ of the pre-reform premium estimate from the SNL data equals $0.35 * \$ 5,871=\$ 2,055$.

${ }^{41}$ Our baseline results suggest a demand slope of $\frac{-\$ 2,393}{0.194}=-\$ 12,335$. The new results suggest a slope of $\frac{-\$ 3,305}{0.194}=$ $-\$ 17,036$, which exceeds our baseline slope by $38 \%$ in absolute terms.
} 
representative population weights in the individual market reported by the DHCFP and find an average semi price elasticity of $-2.25 \%$ per $\$ 100$ increase in premiums. ${ }^{42}$ We reconsider our welfare estimates in two different specifications. In the first specification, we hold on to our coverage estimates and adjust the premiums such that changes in coverage and premiums are consistent with the semi price elasticity from Ericson and Starc (2012). Based on the observed changes in coverage, we conclude that premiums should have decreased by $\$ 1,226$. Since the tax penalty decreased premiums by $\$ 1,250$, we adjust our baseline parameter estimate displayed in Table 7 from $-\$ 1,143$ to $+\$ 24$. This adjustment confirms our intuition. If we extrapolate the empirical price elasticities from the intensive margin to the less elastic extensive margin, then we conclude that the observed change in coverage could have been achieved by a much smaller change in premiums. Using our sufficient statistics formulas we find a full welfare effect of $\$ 555$ and a net welfare gain of $\$ 851 .^{43}$ In the second specification, we retain our baseline premium estimates and adjust our coverage estimates. We conclude that the effective premium decrease of $\$ 2,393$ should have resulted in a coverage gain of $54 \%$, which implies universal coverage in the post-reform period. The respective welfare gains are displayed in the fourth row of Table 7 and suggest a full and a net welfare gain of $\$ 444$ and $\$ 349$ respectively. The welfare estimates in the third and the fourth row exceed our baseline estimates since they rely on the the relatively high price elasticities found at the intensive margin.

Finally, we revisit our welfare analysis based on the cost estimates from our earlier work (Hackmann et al. (2012)). Using hospital claims data from Massachusetts, we find that the slope of the average hospital cost curve equals $-\$ 2,250$. The slope estimate suggests that a coverage increase of 19.4 percentage points reduces the average hospital related costs of the insured population by $0.194 * \$ 2,250=\$ 436.50$. To extrapolate the slope estimate to our sample population we have to make two adjustments. First, we divide the slope estimate by the share of hospital expenditures of total insured health expenditures assuming that the magnitude of adverse selection is similar between hospital related and non-hospital related health care costs. In 2007, hospital expenditures

\footnotetext{
${ }^{42}$ See http://www.mass.gov/chia/docs/cost-trend-docs/cost-trends-docs-2011/premium-report.pdf , page 13.

${ }^{43}$ The net welfare gain exceeds the full welfare gain because the post-reform markup exceeds the pre-reform markup. To calculate the net welfare gain, we calculate the coverage the post-reform coverage level at which the pre-reform markup equals the post-reform markup. In this case, we find a coverage level that exceeds $100 \%$. Therefore, we choose $I^{*, \text { markup }}=100 \%$.
} 
accounted for about $50 \%$ of total insured health expenditures. ${ }^{44}$ Second, we multiply the slope estimate by the actuarial value of the representative insurance plan in Massachusetts individual market. We use the actuarial value of the median plan in the year 2008, see Table 6. Combining these adjustments, we conclude that average insurer costs decrease by $0.194 * \$ 2,250 * \frac{1}{0.5} * 0.726=\$ 633.8$ in response to a coverage increase of 19.4 percentage points. This slope estimate exceeds our baseline estimate by $2 \%$ and suggests slightly larger full and net welfare effects of $\$ 453$ and $\$ 344$ respectively.

Overall, we conclude that our welfare estimates are in the center of welfare predictions that could have been made based on different premium and cost data sources.

\section{Conclusion}

One important theoretical rationale for an individual mandate is that it can mitigate the welfare loss from adverse or advantageous selection by requiring both the healthy and the sick to purchase coverage. On the other hand, recent empirical work on adverse selection finds relatively little welfare loss, suggesting otherwise. Reconciling these two views is both of interest to economists and highly relevant in light of the reliance on an individual mandate in both reforms.

To do so requires (i) a model of adverse selection that incorporates an individual mandate explicitly and is empirically tractable and (ii) a setting to estimate adverse selection at the extensive margin between insurance and uninsurance. The Massachusetts health reform of 2006 gives us a novel opportunity to do just that: examine the impact of a mandate on adverse selection among the entire insured population in a policy very similar to the ACA.

We begin by extending existing theory to derive sufficient statistics for the welfare impact of a mandate. We demonstrate that the change in welfare between pre- and post-reform can be computed based on changes in coverage, premiums, paid claims (cost) and the size of the mandate penalty. Because we have independent measures of premiums and costs, we also incorporate markups in to our welfare analysis, allowing us to distinguish changes in competition from changes in adverse selection. This approach makes the welfare effects of reform theoretically clear, and it also allows us to estimate the impact of reform from available data with a minimum of assumptions. Specifically, we estimate the sufficient statistics using the Massachusetts reform and data

\footnotetext{
${ }^{44}$ See http://www.kff.org/insurance/upload/7692_02.pdf, exhibit 2. We defined hospital care, physician/clinical services and prescription drugs to be the insured health spending categories. If we add the second category to overall hospital services, then up to $84 \%$ of health care spending occurs in the hospital.
} 
on coverage, premiums, and insurer costs from the SNL financial database and the NHIS. Each of these data sets delineates the individual and group markets, allowing us to focus our analysis on the market where we expect reform to have the largest impact (and adverse selection to be most egregious in the absence of reform): the individual market.

We find that the individual market for health insurance was adversely selected prior to reform. The introduction of reform increased coverage by 19.4 additional percentage points. The growth in coverage was associated with a reduction in the average cost of the insured by $\$ 621$. Translating our difference-in-difference estimates into welfare estimates suggests that the representative Massachusetts resident in the individual market was made $\$ 442$ better off. Scaling this estimate by the relevant population in the state suggests a substantial aggregate welfare gain of $\$ 94$ million per year statewide. To put this in perspective, the total welfare gains were $8.4 \%$ of medical expenditures paid by insurers. The welfare gains from reductions in adverse selection alone were $6.4 \%$ of medical expenditures paid by insurers.

Finally, using the same sufficient statistics, we are able to compute the optimal individual mandate penalty; the penalty that induces the level of coverage that would occur without information asymmetries. Given the estimated demand in Massachusetts, the optimum occurs at universal coverage. The statutory penalty $(\$ 1,250)$ would, therefore, have to be increased substantially to the estimated optimum of $\$ 2,190$ and to enhance welfare. While the estimated optimal penalty is higher than the penalty in Massachusetts it is relatively close to the penalty selected under national reform.

Our estimates require a number of assumptions and we rely on data with clear limitations. Nevertheless, our findings are robust to a variety of tests. The methodology developed here is relevant to the evaluation of the Massachusetts reform itself, as we have done. We also expect that future work can build from this framework to model the impact of the ACA as it is implemented nationwide. 


\section{References}

Jean M. Abraham, Pinar Karaca-Mandic, and Michel Boudreaux. Sizing up the individual market for health insurance: A comparison of survey and administrative data sources. Medical Care Research and Review, 2013.

George A. Akerlof. The market for "lemons": Quality uncertainty and the market mechanism. Quarterly Journal of Economics, 84(3):488-500, 1970.

Andrew Beauchamp and Mathis Wagner. Dying to retire: Adverse selection and welfare in social security. 2012 .

M. Kate Bundorf, Jonathan Levin, and Neale Mahoney. Pricing and welfare in health plan choice. American Economic Review, 102(7):3214-3248, December 2012.

Jeffrey Clemens. Regulatory redistribution in the market for health insurance. Working Paper, 2013.

David M. Cutler and Jonathan Gruber. Does public insurance crowd out private insurance? The Quarterly Journal of Economics, 111(2):391-430, 1996.

David M. Cutler and Richard J. Zeckhauser. The Anatomy of Health Insurance, volume 1, Part A of Handbook of Health Economics, chapter 11, pages 563-643. Elsevier, 2000. doi: 10. 1016/S1574-0064(00)80170-5. URL http://www.sciencedirect.com/science/article/pii/ S1574006400801705.

Leemore Dafny. Are health insurance markets competitive? Annual Review of Economics, 100(4): 1399-1431, September 2010.

Liran Einav, Amy Finkelstein, and Mark Cullen. Estimating welfare in insurance markets using variation in prices. Quarterly Journal of Economics, 125(3):877-921, August 2010a.

Liran Einav, Amy Finkelstein, and Jonathan Levin. Beyond testing: Empirical models of insurance markets. Annual Review of Economics, 2:311-336, September 2010b.

Liran Einav, Amy Finkelstein, and Paul Schrimpf. Optimal mandates and the welfare cost of 
asymmetric information: Evidence from the uk annuity market. Econometrica, 78(3):1031-1092, May 2010c.

Keith M. Marzilli Ericson and Amanda Starc. Pricing regulation and imperfect competition on the massachusetts health insurance exchange. NBER Working Paper 18089, 2012.

Keith Marzilli Ericson and Judd B. Kessler. The articulation effect of government policy: Health insurance mandates versus taxes. NBER Working Paper 18913, 2013.

LLC Gorman Actuarial et al. Impact of merging the massachusetts non-group and small group health insurance markets. Massachusetts Division of Insurance and Market Merger Special Commission, Gorman Actuarial, LLC, Marlborough, MA, 2006.

John A. Graves and Jonathan Gruber. How did health care reform in massachusetts impact insurance premiums? American Economic Review Papers And Proceedings, 102(3):508-513, May 2012.

Martin B. Hackmann, Jonathan T. Kolstad, and Amanda E. Kowalski. Health reform, health insurance, and selection: Estimating selection into health insurance using the massachusetts health reform. American Economic Review Papers And Proceedings, 102(3):498-501, May 2012.

Jonathan T. Kolstad and Amanda E. Kowalski. The impact of health care reform on hospital and preventive care: Evidence from massachusetts. Journal of Public Economics, 96:909-929, December 2012a.

Jonathan T Kolstad and Amanda E Kowalski. Mandate-based health reform and the labor market: Evidence from the massachusetts reform. NBER Working Paper 16012, 2012b.

John E. McDonough, Brian Rosman, Fawn Phelps, and Melissa Shannon. The Third Wave of Massachusetts Health Care Access Reform. Health Affairs, 25(6):w420, 2006.

Michael Rothschild and Joseph Stiglitz. Equilibrium in competitive insurance markets: An essay on the economics of imperfect information. Quarterly Journal of Economics, 90(4):629-650, 1976.

Lawrence H. Summers. Some simple economics of mandated benefits. American Economic Review, 79(2):177-183, May 1989. 
Leigh Wachenheim and Hans Leida. The impact of guaranteed issue and community rating reforms on states' individual insurance markets. Technical report, America's Health Insurance Plans, 2012. URL http://www.ahipcoverage.com/wp-content/uploads/2012/03/ Updated-Milliman-Report.pdf. 


\section{A Online Appendix:}

\section{A.1 Plan Heterogeneity and the Extensive Margin}

Our model addresses selection at the extensive margin and abstracts from selection amongst differentiated plans: the intensive margin. Our modeling decision follows naturally from the policy intervention, the individual mandate, which affects the demand for health insurance in general. While our framework may not be accurate in other contexts, we think that the modeling assumptions are sensible in this application for the following two reasons.

First, heterogeneity in plan generosity is limited in the Massachusetts individual health insurance market. According to Ericson and Starc (2012), $80 \%$ of the consumers in this market purchase bronze or silver plans, whose actuarial value varies between $60 \%$ and $70 \%{ }^{1}$ We think that the variation at the intensive margin is small relative to having no health insurance at all.

Second, our modeling framework is consistent with plan heterogeneity if selection at the intensive margin is orthogonal to selection at the extensive margin. If so, we expect that the newly insured consumers purchase health insurance according to the observed market shares of the previously insured, holding the set of offered health insurance plans constant. In this case, we can aggregate heterogenous plans to a single representative plan, which corresponds to a weighted average over the underlying individual plans, weighted by the plan market shares. Our framework models the willingness to pay and the costs of this representative plan.

While our data do not allow us to disentangle differences in preferences between the previously insured and the newly insured on the one hand from changes in plan generosity on the other hand, we notice that the actuarial value of the most popular plans changes only modestly between the pre- and the post-reform years, see Table 6 . Hence, we conclude that on net, these effects do not seem to affect our empirical results considerably.

\section{A.2 Group Market and The Individual Market}

Our model focuses on the individual market and abstracts from changes in the distribution of consumer types that may result from inflows from or outflows to the group market. For instance, Massachusetts health reform introduced an employer mandate, which encourages employers to offer

\footnotetext{
${ }^{1}$ We are not counting silver plus and silver plus and silver select plans
} 
health insurance to their employees, see Kolstad and Kowalski (2012b). Hence, the reform may have created access to employer sponsored health insurance for at least some consumers that purchased health insurance individually in the pre-reform years.

Unfortunately, our data do not allow us to quantify the transition between the individual and the group market. The group market information in the SNL data is incomplete -it does not provide information on self-insured employers- and the NHIS sample population is too small to measure these transitions accurately.

Qualitatively, we interpret our welfare estimates as a conservative lower bound with respect to potential transitions from the individual to the group market for two reasons. First, if consumers switch to the group market, then we will understate the number of insured consumers in the individual market in the post-reform years, which biases our welfare estimates downwards. Second, we think that healthier individuals are more likely to be offered health insurance through their employers. Therefore, we will overstate the marginal costs of the newly insured. In other words, adverse selection would be more pronounced had the switchers remained in the individual market. Hence, the transition of inexpensive consumers to the group market biases our welfare estimates downward as well.

\section{A.3 The Welfare Relevant Area}

This section discusses the change in welfare caused by the elimination of adverse selection, which combines changes in consumer surplus, insurer surplus, and government surplus.

The consumer surplus corresponds to the integral over the difference between the willingness to pay and the market price for buyers minus the tax penalty payments made by the non-buyers. Using the notation from the consumer problem we can express the consumer surplus as:

$$
C S\left(I^{*, t}, \Pi^{t}\right)=\int_{0}^{I^{*, t}}\left(D(x, 0)-D\left(I^{*, t}, \Pi^{t}\right)\right) d x-\Pi^{t} *\left(1-I^{*, t}\right)+Y
$$

where we have substituted the equilibrium premium $P^{(*, t)}$ with the market level demand curve evaluated at the equilibrium coverage level and the respective tax penalty, $D\left(I^{*, t}, \Pi^{t}\right)$. Therefore, 
the change in consumer surplus between the pre-reform and the post-reform period is given by

$$
\begin{aligned}
\Delta C S & =C S\left(I^{*, \text { post }}, \Pi^{\text {post }}=\pi\right)-C S\left(I^{*, \text { pre }}, \Pi^{\text {pre }}=0\right) \\
& =\int_{I^{*, p r e}}^{I^{*, \text { post }}} D(x, 0) d x-I^{*, \text { post }} * D\left(I^{*, \text { post }}, \pi\right)+I^{*, \text { pre }} * D\left(I^{*, \text { pre }}, 0\right)-\pi *\left(1-I^{*, \text { post }}\right),
\end{aligned}
$$

which depends on the demand curve, the pre-reform and post-reform coverage levels, $I^{*, p r e}$ and $I^{*, p o s t}$, and the magnitude of the introduced penalty $\pi$. However, changes in consumer expenditures on health plan premiums, captured by the second and the third term, are not relevant for social welfare as they affect the insurer surplus through changes in revenues as well. Specifically, the insurer surplus refers to the integral over the difference between the market price and the marginal costs of the insured consumer. Therefore, the change in insurer surplus is given by

$$
\begin{aligned}
\Delta I S & =I S\left(I^{*, \text { post }}, \Pi^{\text {post }}=\pi\right)-I S\left(I^{*, \text { pre }}, \Pi^{\text {pre }}=0\right) \\
& =I^{*, \text { post }} D\left(I^{*, \text { post }}, \pi\right)-I^{*, \text { pre }} D\left(I^{*, \text { pre }}, 0\right)-\int_{I^{*, p r e}}^{I^{*, \text { post }}} M C(x) d x,
\end{aligned}
$$

which simply represents the difference between changes in revenues and changes in costs. Finally, the tax penalty payments increase government revenues. We assume that an extra dollar in government revenues adds $\phi$ to social welfare. For our empirical analysis, we assume $\phi=1$ but generally $\phi$ may be smaller or greater than 1 . Therefore, the overall change in welfare is given by

$$
\Delta C S+\Delta I S+\Delta G S=\int_{I^{*, p r e}}^{I^{*, p o s t}}(D(x, 0)-M C(x)) d x-(1-\phi) * \pi *\left(1-I^{*, p o s t}\right),
$$

where $\Delta G S$ refers to the change in government surplus. Intuitively, the mandate increases welfare if the willingness to pay exceeds the marginal costs of the newly enrolled individuals. This welfare change can be visualized simply as a shaded region as shown in Figure 2 after we specify functional forms for the demand curve and the average cost curve. Furthermore, the mandate may reduce welfare if the raised tax penalty revenues do not contribute to social welfare at face value, i.e. $\phi<1$. 


\section{A.4 Sufficient Statistics}

In this section, we derive equation 2 which allows us to express the full welfare effect in terms of a small number of sufficient statistics.

The welfare relevant areas, displayed in equation 1, can be expressed by the primitives of the economic model, which will be particularly relevant in the empirical analysis. We derive these expressions graphically and refer to the distance between the points in figure 2 with an upper bar. In order to use the same notation in different cases we use the following distance norm: $\overline{A B}=A_{x}-B_{x}+A_{y}-B_{y}$, where $A_{x}$ and $A_{y}$ refer to to A's $x$ and $y$ coordinate respectively. The relevant areas equal:

$$
\begin{aligned}
& A B C=-\frac{1}{2} *\left(I^{*, \text { post }}-I^{*, \text { pre }}\right) * \frac{\left(P^{*, \text { post }}-\pi\right)-P^{*, \text { pre }}}{I^{*, \text { post }}-I^{*, \text { pre }}} *\left(I^{*, \text { post }}-I^{*, \text { pre }}\right) \\
& B E D^{\prime} C=(\overline{B D}+\overline{D E}) * \overline{B C}=((\overline{A D}-\overline{A B})+\overline{D E}) *\left(I^{*, p o s t}-I^{*, p r e}\right) \\
& =(\overline{A H}+\overline{H D}-\overline{A B}+\overline{D E}) *\left(I^{*, \text { post }}-I^{*, p r e}\right) \\
& =\left(\left(P^{*, p r e}-A C^{*, p r e}\right)-\left(\frac{M C^{*, p o s t}-M C^{*, p r e}}{I^{*, p o s t}-I^{*, p r e}}-\frac{A C^{*, \text { post }}-A C^{*, \text { pre }}}{I^{*, \text { post }}-I^{*, \text { pre }}}\right) * I^{*, \text { pre }}\right. \\
& \left.+\frac{\left(P^{*, \text { post }}-\pi\right)-P^{*, \text { pre }}}{I^{*, \text { post }}-I^{*, \text { pre }}} *\left(I^{*, \text { post }}-I^{*, \text { pre }}\right)-\frac{M C^{*, \text { post }}-M C^{*, \text { pre }}}{I^{*, \text { post }}-I^{*, \text { pre }}} *\left(I^{*, \text { post }}-I^{*, \text { pre }}\right)\right) \\
& \text { * }\left(I^{*, p o s t}-I^{*, p r e}\right) \\
& D E D^{\prime}=-\frac{1}{2} *\left(I^{*, \text { post }}-I^{*, \text { pre }}\right) * \frac{M C^{*, \text { post }}-M C^{*, \text { pre }}}{I^{*, \text { post }}-I^{*, \text { pre }}} *\left(I^{*, \text { post }}-I^{*, \text { pre }}\right) .
\end{aligned}
$$

Because of the linear cost structure, we have $\frac{M C^{*, p o s t}-M C^{*, p r e}}{I^{*, p o s t}-I^{*, p r e}}=2 * \frac{A C^{*, \text { post }}-A C^{*, p r e}}{I^{*, p o s t}-I^{*, p r e}}$. Combining the previous terms, we can express the welfare change as:

$$
\begin{aligned}
\Delta W_{\text {full }} & =\left(P^{*, \text { pre }}-A C^{*, \text { pre }}\right) *\left(I^{*, \text { post }}-I^{*, \text { pre }}\right) \\
& -\left(A C^{*, \text { post }}-A C^{*, \text { pre }}\right) *\left(I^{*, \text { pre }}+\left(I^{*, \text { post }}-I^{*, \text { pre }}\right)\right) \\
& +\frac{1}{2} *\left(\left(P^{*, \text { post }}-\pi\right)-P^{*, \text { pre }}\right) *\left(I^{*, \text { post }}-I^{*, \text { pre }}\right)
\end{aligned}
$$




\section{A.5 Post-Reform Coverage Under Pre-Reform Markup}

In this section, we derive the formula for the post-reform coverage level under the pre-reform markup, see equation 4 .

To find the post-reform coverage level under the pre-reform markup, we set the post-reform demand curve equal to the average cost curve plus the pre-reform markup. In our linearized framework, we can express these curves as follows:

$$
\begin{gathered}
D(I, \pi)=\alpha_{0}+\alpha_{1} * I+\pi \\
A C(I)+\operatorname{load}^{*, p r e}=\beta_{0}+\beta_{1} * I+P^{*, p r e}-A C^{*, p r e} .
\end{gathered}
$$

Here, $\alpha_{0}$ and $\beta_{0}$ are intercept terms and $\alpha_{1}$ and $\beta_{1}$ are the respective slope terms. Solving for coverage $I$, we find:

$$
I^{*, \text { markup }}=\frac{\beta_{0}-\alpha_{0}+P^{*, \text { pre }}-A C^{*, \text { pre }}}{\alpha_{1}-\beta_{1}}-\pi * \frac{1}{\alpha_{1}-\beta_{1}} .
$$

We also now that $I^{*, \text { markup }}=I^{*, \text { pre }}$ for $\pi=0$. Therefore, we have:

$$
I^{*, \text { markup }}=I^{*, \text { pre }}+\pi * \frac{I^{*, \text { post }}-I^{*, \text { pre }}}{\left(A C^{*, \text { post }}-A C^{*, \text { pre }}\right)-\left(\left(P^{*, \text { post }}-\pi\right)-P^{*, \text { pre }}\right)} .
$$

\section{A.6 Welfare Effects When Coverage Exceeds the Optimum}

In this section, we show that our welfare formula, equation 1, extends to the case in which coverage exceeds the social optimum, see Figure 4.

To see that the size of the full welfare effect is given by equation 2 , notice that the light gray shaded area equals the area of the triangle $\mathrm{ABC}$ minus the polygon area DBCX. To derive the full welfare effects we also subtract the dark gray shaded triangle area XD'C. Finally, the union of the polygon area $\mathrm{DBCX}$ and the triangle XD'C equal the union of the rectangle area EBCD' (-BED'C) and the triangle area DED'. In summary,

$$
\Delta W=A B C-\left(D B C X+X D^{\prime} C\right)=A B C-\left(E B C D^{\prime}+D E D^{\prime}\right)=A B C-\left(-B E D^{\prime} C+D E D^{\prime}\right),
$$


which is equivalent to equation 1.

\section{A.7 Optimal Coverage And Optimal Penalty}

In this section, we derive the formulas for optimal coverage and the optimal tax penalty displayed in equations 5 and 6 respectively.

To find the optimal insurance coverage we first consider an interior solution that corresponds to the intersection of the pre-reform demand curve and the marginal cost curve. Using the notation from the previous section, we find that:

$$
\begin{aligned}
\alpha_{0}+\alpha_{1} * I & =\beta_{0}+2 * \beta_{1} * I \\
\Longleftrightarrow \quad I^{*, o p t} & =\frac{\beta_{0}-\alpha_{0}}{\alpha_{1}-2 \beta_{1}}
\end{aligned}
$$

Adding and subtracting $P^{*, p r e}-M C^{*, p r e}$ in the numerator we find that:

$$
\begin{aligned}
I^{*, \text { opt }} & =\frac{\beta_{0}-\alpha_{0}+\left(P^{*, \text { pre }}-M C^{*, \text { pre }}\right)}{\alpha_{1}-2 \beta_{1}}-\frac{\left(P^{*, \text { pre }}-M C^{*, \text { pre }}\right)}{\alpha_{1}-2 \beta_{1}} \\
& =I^{*, \text { pre }}+\frac{\left(P^{*, \text { pre }}-M C^{*, \text { pre }}\right) *\left(I^{*, \text { post }}-I^{*, \text { pre }}\right)}{2\left(A C^{*, \text { post }}-A C^{*, \text { pre }}\right)-\left(\left(P^{*, \text { post }}-\pi\right)-P^{*, \text { pre }}\right)} .
\end{aligned}
$$

Adding and subtracting $A C^{*, p r e} *\left(I^{*, p o s t}-I^{*, p r e}\right)$ to the numerator of the ratio, we can rewrite the second term as:

$\frac{\left(P^{*, \text { pre }}-A C^{*, \text { pre }}\right) *\left(I^{*, \text { post }}-I^{*, \text { pre }}\right)}{2\left(A C^{*, \text { post }}-A C^{*, \text { pre }}\right)-\left(\left(P^{*, \text { post }}-\pi\right)-P^{*, \text { pre }}\right)}+\frac{\left(A C^{*, \text { pre }}-M C^{*, \text { pre }}\right) *\left(I^{*, \text { post }}-I^{*, \text { pre }}\right)}{2\left(A C^{*, \text { post }}-A C^{*, \text { pre }}\right)-\left(\left(P^{*, \text { post }}-\pi\right)-P^{*, \text { pre }}\right)}$

and using the linearity of the average cost curve, we have:

$$
A C^{*, \text { pre }}-M C^{*, \text { pre }}=-\frac{A C^{*, \text { post }}-A C^{*, \text { pre }}}{I^{*, \text { post }}-I^{*, \text { pre }}} * I^{*, \text { pre }} .
$$

Finally, we consider that the optimal coverage is bounded from below and above by one and zero respectively. Combining these terms, we find that the optimal insurance coverage can be expressed as shown in equation 5 . The optimal tax penalty shifts the equilibrium coverage level to the optimum. To find this penalty, we set the post-reform demand curve, evaluated at the optimal 
coverage level, equal to the average cost plus the post reform markup:

$$
D\left(I^{*, o p t}, \pi\right)=A C\left(I^{*, o p t}\right)+P^{*, p o s t}-A C^{*, p o s t} .
$$

and solve this equation for $\pi$. We have:

$$
\begin{aligned}
\alpha_{0}+\alpha_{1} * I^{*, \text { opt }}+\pi & =\beta_{0}+\beta_{1} * I^{*, \text { opt }}+P^{*, \text { post }}-A C^{*, \text { post }} \\
\Longleftrightarrow \quad P^{*, \text { pre }}+\alpha_{1}\left(I^{*, \text { opt }}-I^{*, \text { pre }}\right)+\pi & =A C^{*, \text { pre }}+\beta_{1}\left(I^{*, \text { opt }}-I^{*, \text { pre }}\right)+P^{*, \text { post }}-A C^{*, \text { post }} \\
\Longleftrightarrow \pi^{*, \text { opt }} & =\left(P^{*, \text { post }}-P^{*, \text { pre }}\right)-\left(A C^{*, \text { post }}-A C^{*, \text { pre }}\right) \\
& +\frac{A C^{*, \text { post }}-A C^{*, \text { pre }}-\left(\left(P^{*, \text { post }}-\pi\right)-P^{*, \text { pre }}\right)}{I^{*, \text { post }}-I^{*, \text { pre }}} *\left(I^{*, \text { opt }}-I^{*, \text { pre }}\right)
\end{aligned}
$$

\section{A.8 Welfare Effects Under Advantageous Selection}

In this section, we show that our welfare formulas apply to the case of advantageous selection as well.

Figure A1 describes the welfare effects under advantageous selection. In this case both the

Figure A1: Advantageous Selection And Welfare

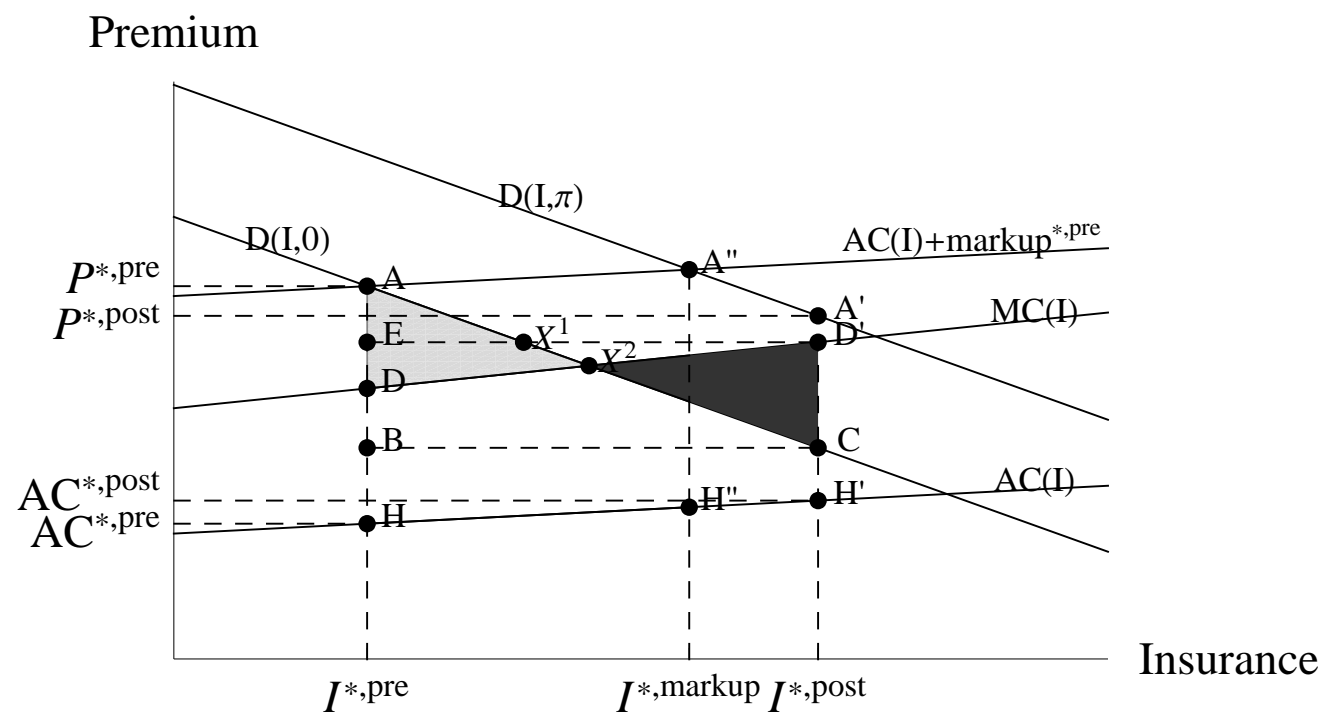

marginal and the average cost curve slope upward. The full welfare effect is now given by the light 
gray area minus the dark area. This can simply be expressed in terms of two triangles:

$$
\Delta W_{f u l l}=A D X^{2}-X^{2} D^{\prime} C=A B C+B E D^{\prime} C-D E D^{\prime}
$$

To see the second equality, notice that the areas $B E D^{\prime} C$ and $D E D^{\prime}$ are negative according to our earlier definition. To see this check the derivations in section A.4. If we add the (negative) area $B E D^{\prime} C$ to the triangle $A B C$ then the net area can be expressed as:

$$
A B C+B E D^{\prime} C=A E X^{1}-X^{1} D^{\prime} C
$$

If we now subtract the (negative) area $D E D^{\prime}$, then we have:

$$
A B C+B E D^{\prime} C-D E D^{\prime}=A E X^{1}-X^{1} D^{\prime} C-D E D^{\prime}=A E X^{2}-X^{2} D^{\prime} C .
$$

\section{A.9 Trends in Guaranteed Issue States}

Figures A2,A3, and A4 show the relevant trends in enrollment, premiums, and claim expenditures in Massachusetts relative to the other states with guaranteed issue and community rating regulations.

The trends in the control states look very similar to the national trends displayed in Figures 5, 6 , and 7 .

\section{B Appendix: Bootstrap}

To assess the precision of our welfare estimates, we derive the distribution of the welfare effects via bootstrap. We hereby proceed as follows. First, we apply a block bootstrap approach to the SNL data and draw entire state clusters with replacement from the state-year level sample. For each sample, we first draw post-reform coverage levels for Massachusetts and the other states. Specifically, for each state within the sample, we draw $N_{\text {state }}$ observations from a Bernoulli distribution with mean $\mu_{\text {state }}$ and construct the arithmetic mean. Here, $N_{\text {state }}$ and $\mu_{\text {state }}$ refer to the number of observations and the coverage level in the post-reform population for the given state respectively.

Second, we use the respective post-reform coverage levels to normalize the enrollment trends 
Figure A2: Insurance Coverage Amongst GI States

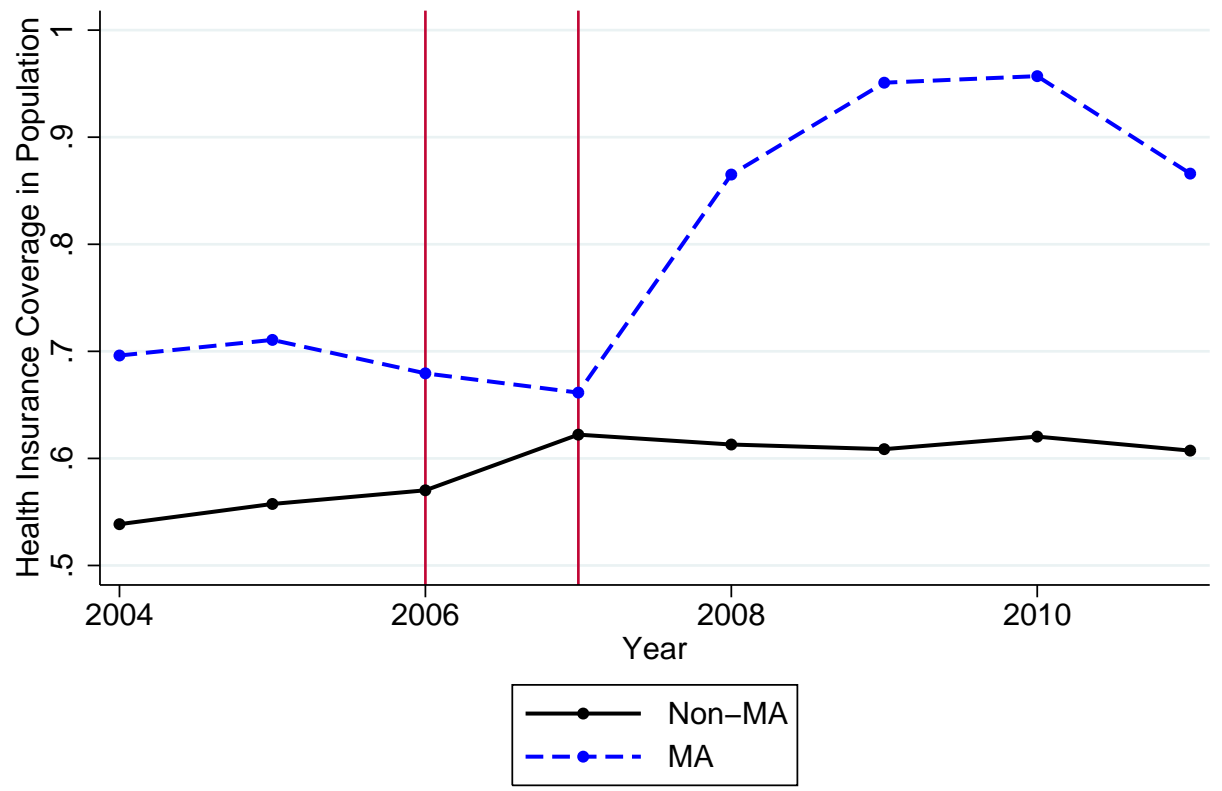

in the sample, conduct the relevant difference-in-differences regressions and save the estimated the pre-reform levels in Massachusetts and the estimates for $\gamma^{k}$.

Third, we calculate the full and the net welfare effect using the outlined formulas. Finally, we report the median, the 2.5 , and the 97.5 percentile of the estimated welfare effect distributions. We repeat this procedure for different penalty values and report the results in Table 3.

Finally, we notice positive slope estimates for the average cost curve in some bootstrap samples. In these samples, we would conclude that Massachusetts individual market was advantageously selected in the pre-reform years. In order to provide adequate confidence intervals, we verify in Section A.8 that our formulas apply in the case of advantageous selection as well. 
Figure A3: Annual Premiums Amongst GI States

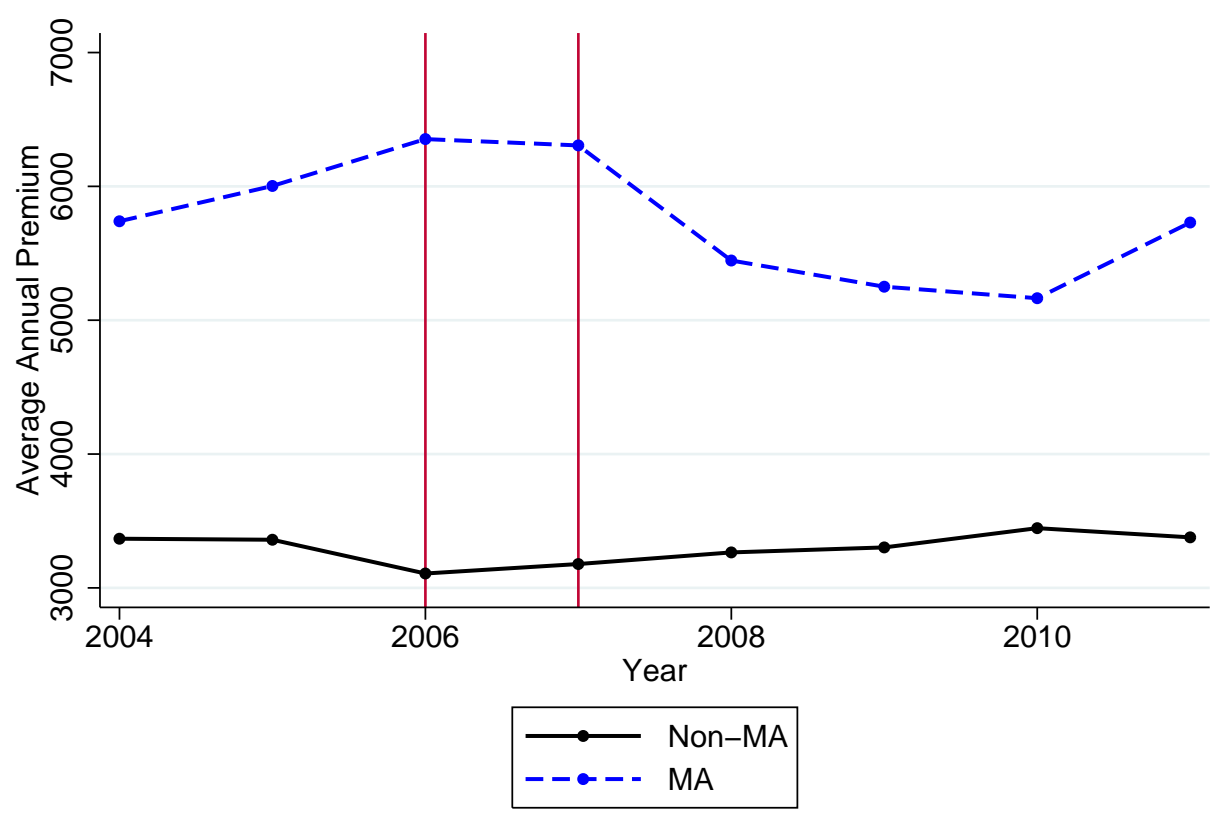


Figure A4: Annual Average Claim Expenditures Amongst GI States

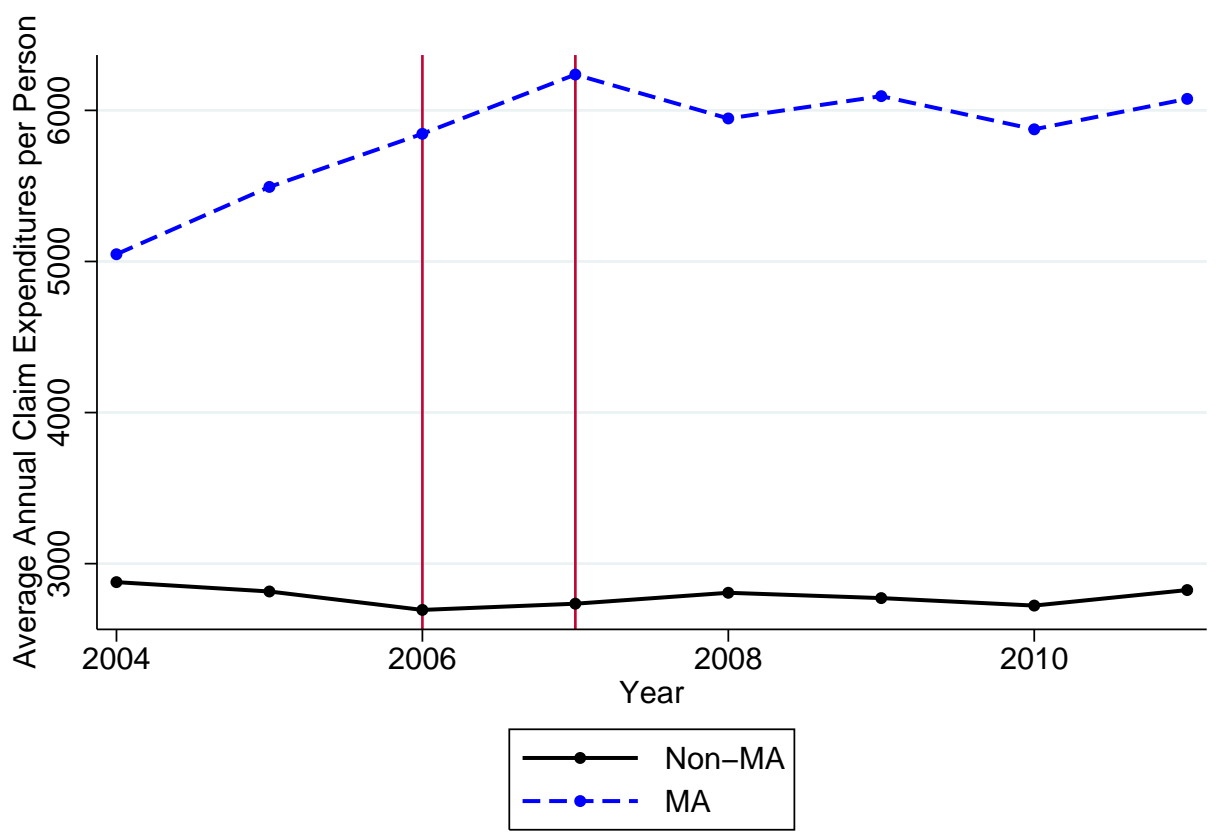

